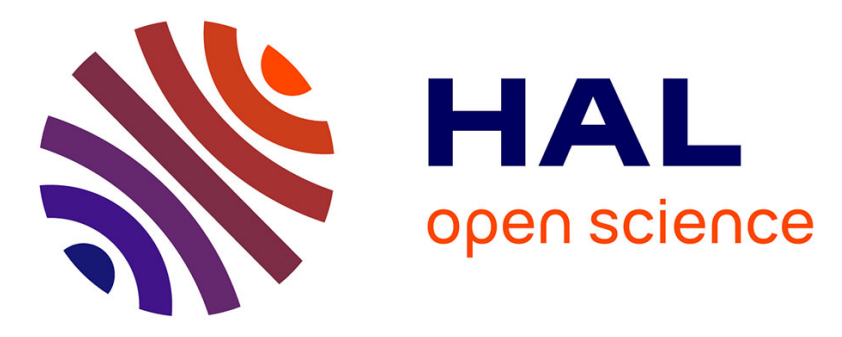

\title{
Synthesis of Fibrous Complex Structures: Designing Microstructure to Deliver Targeted Macroscale Response
}

Francesco Dell'Isola, David Steigmann, Alessandro Della Corte

\section{- To cite this version:}

Francesco Dell'Isola, David Steigmann, Alessandro Della Corte. Synthesis of Fibrous Complex Structures: Designing Microstructure to Deliver Targeted Macroscale Response. Applied Mechanics Reviews, 2016, 67 (6), 21 p. hal-01284511

\section{HAL Id: hal-01284511 \\ https://hal.science/hal-01284511}

Submitted on 7 Mar 2016

HAL is a multi-disciplinary open access archive for the deposit and dissemination of scientific research documents, whether they are published or not. The documents may come from teaching and research institutions in France or abroad, or from public or private research centers.
L'archive ouverte pluridisciplinaire HAL, est destinée au dépôt et à la diffusion de documents scientifiques de niveau recherche, publiés ou non, émanant des établissements d'enseignement et de recherche français ou étrangers, des laboratoires publics ou privés. 
Francesco dell'Isola

DISG,

University of Rome La Sapienza Rome 00184, Italy

e-mail: francesco.dellisola@uniroma1.it

\author{
David Steigmann \\ Faculty of Mechanical Engineering \\ University of California, \\ Berkeley, CA 94720-1740 \\ e-mail: dsteigmann@berkeley.edu
}

\begin{abstract}
Alessandro Della Corte
DIMA

University of Rome La Sapienza,

Rome 00185, Italy

e-mail: alessandro.dellacorte@uniroma1.it
\end{abstract}

\section{Synthesis of Fibrous Complex Structures: Designing Microstructure to Deliver Targeted Macroscale Response}

In Mechanics, material properties are most often regarded as being given, and based on this, many technical solutions are usually conceived and constructed. However, nowadays manufacturing processes have advanced to the point that metamaterials having selected properties can be designed and fabricated. Three-dimensional printing, electrospinning, self-assembly, and many other advanced manufacturing techniques are raising a number of scientific questions which must be addressed if the potential of these new technologies is to be fully realized. In this work, we report on the status of modeling and analysis of metamaterials exhibiting a rich and varied macroscopic response conferred by complex microstructures and particularly focus on strongly interacting inextensible or nearly inextensible fibers. The principal aim is to furnish a framework in which the mechanics of $3 D$ rapid prototyping of microstructured lattices and fabrics can be clearly understood and exploited. Moreover, several-related open questions will be identified and discussed, and some methodological considerations of general interest are provided.

\section{Introduction}

1.1 Past Achievements and New Challenges. Since its birth, hard science has developed in close relation with emerging technology [1]. It is indeed a leitmotiv in the History of Science that the increase of phenomenological evidence entailed by the development of new technological possibilities has first put in crisis the existing scientific paradigms and then gradually led to new ones. This was exactly what happened, for instance, when scientific technology was born in the Hellenistic World, when modern Mechanics arose in the age of Galileo or when thermodynamics was elaborated in the early 19th century. In all these cases, the most evident sign of the success of the conceptual revolution is the fact that the new ideas which were elaborated to describe and design technological novelties (as, for instance, catapults, bombards, or steam engines) are nowadays integrated in the same theoretical framework of so-called classical physics. However, one should not forget the long and troublesome process that led to this integration.

In our opinion, Mechanics is about to experience a similar conceptual revolution. The newly arisen technological possibilities in controlling the properties of materials at the micro- and nanoscale are pushing for the development of new theoretical models. In particular, the novelties made possible by advanced manufacturing techniques developed in the recent past are forcing us to reconsider our ideas about the position of theoretical and applied mechanics in relation to technology. The behavior of objects produced by means of these methods, more often than not, is indeed exotic and peculiar from the classical point of view.

Whereas for thousands of years, material properties have been regarded as being given, it is clear that manufacturing processes have now advanced to the point that one can design and fabricate materials exhibiting properties that are not directly found in nature, i.e., so-called metamaterials. Three-dimensional printing, electrospinning, self-assembly, and many other advanced manufacturing techniques are raising a number of scientific questions, which have to be answered if the potential of existing and foreseeable developments in manufacturing is to be fully realized. One has to admit that, as sometimes happens in the History of Science, technological innovation is today ahead of scientific modeling in this regard. Multiscale and multiphysics structures are able to exhibit a wide range of peculiar behaviors and may involve an extraordinary level of complexity in their internal organization. The need to design and construct metamaterials calls thus for major advancements in the mechanics and physics of solids and fluids, in mathematical and numerical modeling, and in advanced computer-aided technology. Moreover, to meet this challenge, a strong theoretical foundation and a realistic and up-to-date knowledge of what is concretely feasible today are essential.

The present work is mainly intended as a review on fabrics and in general on fibrous materials. However, when speaking of metamaterials, many different systems come to mind, as, for instance, acoustoelastic metamaterials intended for wave manipulation (photonic, phononic effects, etc.) and others (e.g., truss networks, composites, mechanical metamaterials, etc.). In order to outline a much more general picture, we will provide some example of metamaterials from a broader class than fabrics which, without any claim of exhaustiveness, can help the reader to get a better understanding of a very large research area.

From the point of view of a theoretical approach, one of the main ideas emerging up to the present time is a unifying variational approach, which is applicable to a wide and diverse range of problems. On this subject, Refs. [2-9] are classical references; a recent overview is provided in Refs. [10,11], while interesting recent results related to complex materials are provided in Refs. [12-19]. Existence and uniqueness of solutions in the variational setting are studied in Refs. [20-22] concerning surface effects, in Ref. [23] in case of micropolar continua, and in Ref. [24] in a more general context. Moreover, inelastic processes have also been described within the variational framework, and in this connection, relevant contributions are given in Ref. [25], where aspects, such as plastic deformation, nonNewtonian viscosity, rate sensitivity of plastic flow, and hardening, are covered. 
1.2 The Need to Reorganize a Complex Subject. The absence of a general order founded on a common framework is a common feature of emerging topics and novel research fields. This is exemplified by the design of metamaterials; this is not a mere problem of terminology, but may also form barriers to communication between different groups of researchers; this is indeed one of the major problems of modern science.

A primary purpose of the present review is to show that problems attacked by means of a variety of approaches, in seemingly different research fields are, under the surface, just different aspects of the same general problem.

Among the most used "labels" for today's research in applied mechanics we indeed find:

- advanced materials [26-29],

- architectured materials [30-36],

- optimized materials [37-39],

- metamaterials [40-44],

- smart materials [45-49],

- multiscale materials [50-53],

- multiphysics materials [54-68],

- materials with negative mechanical constitutive coefficients (stiffness, modulus, Poisson ratio, etc.) [69-73],

- composite materials [74-78], and

- complex materials [79-85].

Regarding theoretical counterparts, we have, for instance:

- generalized continua [86-94],

- microstructured continua [2,95-109],

- continua with microstrains $[110,111]$

- higher gradient continua [112-119],

- Cosserat continua [120-127], and

- micropolar continua [128-131].

Of course, it would be wrong to say that all these labels refer to exactly the same scientific content, even if in some cases, as for instance the last two, they are almost exact synonyms (for works explicitly aimed at the identification of intersections between some of the previous fields, reference may be made to, e.g., Refs. $[89,132-138])$. Rather, we want to underline the common motivations behind their origins, together with their shared goals.

In the opinion of the authors, the real challenge for today's theoretical and applied mechanics is expressed by the following:

Mission statement - to select the desired behavior of a material by means of the choice of its governing equations, and subsequently to synthesize and manufacture a microstructure or a complex multiphysics system whose behavior is suitably described by the chosen equations.

This mission statement is, sometimes in an indirect way, at the basis of the fields identified by the previous labels and constitutes their common underlying foundation. In our opinion, this kind of perspective provides a needed guide in what seems to be a very complicated spectrum of problems. If one keeps clear the ultimate target, the subtleties and the technicalities which distinguish one label from the other will not distract attention from the actual scientific content, and it will be much easier to translate methods and tools from one area to another, thereby strengthening the arsenal for meeting the challenges.

\section{The Hypotheses at the Basis of Mechanics and Their Relation With Existing Technology}

Mathematical modeling capabilities have shaped the technologies of every advanced society [1]. The great advancement of Illuministic engineering was based on solid mathematical grounds and produced a grand economical and technological development. Western civilization was characterized by an Archimedean mathematical description of both phenomena and engineering artifacts. However, until very recent times, mathematical modeling has been limited to the description of pre-existing materials (see Ref. [139] for a general introduction in material selection).
Therefore, the simplifying assumptions which were the basis of engineering in the Illuministic era and in the subsequent Industrial Revolution were deeply founded in the observed phenomenology and became a paradigm of scientific and technological thought. The assumptions conjectured by the founders of modern engineering sciences (Cauchy, Poisson, Navier, Maxwell, Piola, etc.) were so deeply rooted in the minds of scientists and engineers that they became basic doctrine.

Indeed, several lines of inquiry have ceased to evolve, precisely because of the depth of these roots, even if the emergence of computer-aided manufacturing rendered them rather obsolete (for a general reference on the topic, see Ref. [140]). An important example is that of external contact action. For scientists accustomed to classical Cauchy continua, whose deformation energy depends on the first gradient of the displacement, external contact actions are essentially surface forces; however, when dealing with complex microstructures which lead, in their homogenized limit, to higher gradient models (refer to Sec. 1.1), the set of possible external contact actions is richer and may include line forces, concentrated forces, double forces, and objects of higher order [141]. Another way to express the previous statement is: once you can manufacture (by 3D printing, electrospinning, or any other novel technical possibility) an object with a microstructure which, macroscopically seen as a continuum, can sustain double forces (or higher order ones), you cannot anymore neglect them in your theoretical constructions. This means that you have to rebuild your set of assumptions in order to enrich the consequences you can deduce from them. It is a clear example of what is intended by the title of the present section: the technological possibilities, as already observed in Sec. 1, determine the most appropriate set of hypotheses to be assumed as a foundation for the theoretical construction of mechanics. As a consequence, it is insufficient to be limited to a certain formulation for purely abstract reasons, without taking into consideration the effects of the introduction of novel technologies. A notable example is given in Ref. [142], where materials with unusual response to elastic waves (requiring a suitable generalization of elementary dynamics' concepts) are investigated.

An important conceptual revolution in connection with the emergence of new technology, methodologically not too different from what we are discussing, has already occurred. In the early 1940 s of the 20th century, the competition between analog computers and Turing-von Neumann machines forced the supporters of analog computing to change their paradigms. Inspired by the need to obtain solutions to complex partial differential equations (PDEs) or ordinary differential equations (ODEs) needed for the construction of scientific experiments (see, for instance, Ref. [143]) or for large-scale production designing [144], many scientists could not wait for the final establishment of the superiority of digital computers and were obliged to build, or, as they often said, to synthesize analogous electric circuits governed by a given set of mathematical equations for the purpose of computing.

This process, which was historically important in the emergence of modern computing, is methodologically analogous to the approach entailed by the aforementioned mission statement, whose aim is indeed to choose the desired behavior of the materials by means of the choice of its governing equations, and subsequently to synthesize a microstructure or a complex multiphysics system whose behavior is suitably described by the chosen equations. The main difference lies in the wider generality of the systems to be considered today, and, as a consequence, the greater sophistication of the necessary theoretical tools.

\section{Three Approaches to Accomplish the Objective}

In the context of Applied Mechanics, three different approaches can be used to meet the challenge expressed by the foregoing mission statement.

3.1 Physical Modeling. This approach consists of conjecturing, by means of physical intuition and experience, the structure 
of a system performing a given task and then proving the validity of the conjecture by means of prototyping and experimental evidence. Of course, in this approach the proper use of numerical simulations is very important to direct physical intuition toward the most promising cases. Powerful methods allowing rapid assessment of the main quantitative characteristics of complex mechanical systems are today available, and among them one of the most universal is the Finite-Element Analysis, whose flexibility is ideal for dealing with geometrically complex systems such as those related to metamaterials (see Ref. [145] for a historically important reference, and Refs. [146-154] for interesting recent applications). Finite elements with suitable interfaces can also be employed for modeling fracture phenomena, as done in Refs. $[155,156]$. Finally, especially useful can be the introduction of elements with high regularity properties as, for instance, those used in isogeometric analysis (see, e.g., Refs. [157-164]). Another very successful computational tool is represented by Molecular Dynamics, which is based on the numerical study of systems constituted by a very large number $N$ of elements. The numerical computation of the trajectories of particles in the ordinary $6 \mathrm{~N}$ dimensional phase space of positions and momenta employs the classical mechanics laws of motion (for an introduction, see Ref. [165]). Finally, especially concerning inelasticity, very important are computational scale-bridging methods (such as CADD, QC, MADD, and DDD, see Ref. [166] for an example with the discussion of some general problems in models comparison), which have emerged from the need to apply classical mechanics to small-scale systems.

3.2 Models of Generalized Continua. The foregoing approach is probably most effective when a major advance has already been achieved, and only simple refinements remain to be performed. When, instead, completely new concepts are to be applied to achieve technological progress, a true change of paradigm is needed, and such a change can be obtained only by re-examining a substantial part of engineering science. It seems that to this end the basis of continuum mechanics must be revisited, to effectively restart a line of research initiated by Piola [167]. Even if seemingly not consciously, the revival of Piola's ideas is already in progress. The currently active field of Peridynamics furnishes a particularly fruitful example (see, for instance, Refs. [168-172] for relevant results and Ref. [134] for a historical perspective). Peridynamics is indeed the modern name given to Piola's most general continuum mechanics proposed by him as a sound tool for investigating the mechanics of deformable bodies. Standard continuum mechanics, though providing a most powerful conceptual framework, seems to have exhausted its propulsive thrust, at least insofar as macromodeling is concerned. Naturally, once suitable continuum models have been introduced on the basis of the known smaller-scale structure, then only discrete numerical methods will be able, in the general case, to furnish detailed predictions of the relevant phenomena occurring in the contemplated technologies. Some purely academic exercises can be solved with analytical or semi-analytical methods, but their impact cannot be regarded as being substantially relevant in technological applications. Rather, their importance stems mainly from the fact that they furnish benchmarks for numerical codes.

3.3 Dimension Reduction of Discrete Models. Once the relevant small-scale substructure has been identified, providing a purely conceptual basis for the theoretical description of a complex system, the most important modeling step consists in finding a discrete model to represent the important aspects of the phenomenology. Normally, such a discrete system has a very large number of degrees-of-freedom, say $q_{i}(i=1, \ldots, N)$, and even if very powerful supercomputers could apply them to a few cases of academic interest, their systematic application to engineering problems is still not feasible. Therefore, one contemplates the introduction of a lower dimensional discrete model (having coordinates $Q_{h}, h=1, \ldots, n$, with $\left.n \ll N\right)$ and a reduction kinematic map (also known as a "handshake step" in multiscale modeling), allowing for the determination of all of the $q_{i}$ once the $Q_{h}$ are given (interesting results along these lines may be found in Ref. [173]). All of the capabilities of the modeler are, in this context, bound to the fidelity of this reduction map. If both systems are Lagrangian (possibly extended to include a Hamilton-Rayleigh dissipation potential), the reduction map will immediately produce the Lagrangian of the reduced system and will provide a useful computational tool. In some cases, rigorous mathematical results may also be available to prove that when one or more parameters tend to zero, the introduced procedure actually yields a suitable approximation.

3.4 An Overview of the Three Approaches. Each one of the aforementioned approaches finds a natural role in the research work according to its intrinsic merits. In most of the cases, the synergistic interaction of all of them, which is the basis of the Archimedean-Galilean method, is a necessary condition for scientific progress. A way to concretely realize the purposes described concisely in Secs. 3.1, 3.2 and 3.3 can consist in setting up a program for producing 3D-printed prototypes, such as that shown in Fig. 1 (see below for details). The inspiration for the fine structure of the printed specimens can often be drawn from the available technology of fiber-reinforced composites and the available literature in the field of architectured materials $[32,109,139,174]$. Suitable modifications and parameter variations can be tested by measuring the mechanical properties of prototypes. Further, simple piezoelectromechanical systems with actuators of smaller size than those used in Refs. [175-177] can be constructed to test the feasibility of exploiting multiphysics to achieve desired global macroscale properties. Of course, the characteristic length scale that can be attained with the aforementioned methods cannot reach nanodimensions. However, the conceived prototyping, once guided by a suitable rescaling theoretical methodology, could yield important insights into the effectiveness of the considered concepts. For example, it is well known that electrospinning cannot currently produce precisely designed complex fabrics at the nanoscale. However, it can be usefully employed to explore some nanophenomenology and to yield an understanding of some relevant properties (for a discussion concerning size-related surface effects, see Sec. 6).

\section{Examples of Possible Implementations of the Mission Statement}

The Mission Statement above expressed in its general form can be realized in several concrete ways. A classical challenge, and

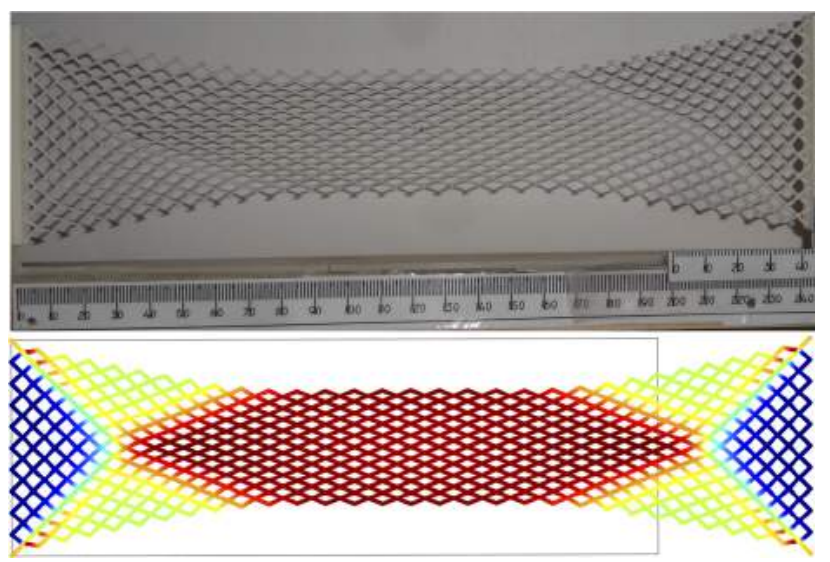

Fig. 1 Bias test on a 3D-printed pantographic sheet (top) and simulation, as studied in Ref. [358] (original picture by the authors); we remark that the picture is relative to a continuum simulation, and that the curves represent sets of material points which are straight lines in the reference configuration 
still one of the most important ones, is to find materials with prescribed/optimized constitutive characteristics (e.g., stiffness, strength, toughness, dispersions relations, etc.). Moreover, several other problems can nowadays be addressed:

(1) To find a material which is able to damp mechanical vibrations by means of a granular microstructure [178] or by transforming mechanical energy into electromagnetic energy via piezoelectric transduction [175,179-185].

(2) To find a material which exhibits, at least in some directions, a large ratio between weight and fracture toughness [186-195].

(3) To find a deformable porous material saturated by an electrically or magnetically active nematic fluid, to enhance Darcy dissipation to control the propagation of electro- or magneto-nematic waves [196-199].

(4) To find an adaptive material endowed with an embedded sensing system activating variations in mechanical constitutive parameters; for example: a beam with a section moment of inertia that can be modified by the actuation driven by mechanical wave propagation or by an electrical signal, or other kinds of smart materials for bone fracture repair purposes [200-214].

(5) To design a multiscale fabric constituted by a beamlike substructure whose deformation energy depends on $n$th gradient of displacement field, and to exploit these structural elements to form materials exhibiting nonstandard dispersion effects, possibly including frequency band gaps.

(6) To find a material constituted by nearly inextensible fibers, which is able to resist shear and elongation by storing deformation energy in the form of fiber bending energy [215].

For each one of the previous targets, some results and potentially useful tools are already available in the literature, and the references provided were intended as a (partial) coverage of them. In addition, it should also be pointed out that, in almost every one of the considered problems, the elementary theory of the beam can still play a fundamental role. It is indeed by suitably generalizing classical beam models that richer theories, required for the study of metamaterials, are often developed (on generalized beam theory, see, e.g., Refs. [216-219]).

\section{Standard Methods in Material Designing and Related Challenges}

The usual procedure, when dealing with the mathematical design and description of new technology, in particular considering microstructured objects, consists of the following steps:

(1) To select a promising microstructure which is practically realizable by means of existing (or foreseeable) manufacturing techniques; this may be done by means of intuition, experience, or by the methods of structural optimization $[32,109,139]$.

(2) To identify the smallest length scale at which a field model could be introduced, at least in principle. This field theory can be classical or based on molecular dynamics, depending on the characteristic structural length scale and the required accuracy. Usually, this model cannot be employed to make predictions because of the enormous computational effort required.

(3) To use a discrete mesoscale model for describing the behavior of the considered complex system in an approximate way; this mesomodel must incorporate the most relevant overall behavior of the previously introduced smallest length-scale model.

(4) To build an averaged continuous macromodel based on a certain set of simplifying assumptions, using an appropriate homogenization process, asymptotic expansions, and perturbative analyses, as done, for instance, in Ref. [192] in the case of pantographic structures (see below; useful general results based on perturbative methods are provided in Refs. [220-223]).

(5) To study the continuous model via numerical methods; i.e., to discretize it with one of the standard techniques (finitedifference method or finite-element method (FEM), isogeometric, etc.).

(6) To compare the numerical solutions with experimental data and to refine the model accordingly.

The previous scheme, going from micro- to macroscale, is not the only one possible, and indeed other kinds of approaches exist (e.g., the so-called "scale-bridging" models, where two different scales, a coarser one and a finer one, are used for the description of the system [224]).

Concerning the aforementioned scheme, it is at least reasonable to question the universal validity of the aforementioned procedure. It can be conjectured, indeed, that the passages 3-5 could be made shorter by avoiding the intermediate continuum model.

Let us discuss this point in detail. Because of the high degree of complexity of the structures which can be produced today, it is almost always impossible to find analytical or semi-analytical solutions to the equations governing the micromodel (discussed in point 2), and in fact numerical analysis (point 5) has gradually become the only means by which the model interacts with experiments. While in the previous two or more centuries, in the engineering sciences the continuous model has been viewed as the most appropriate scientific image of reality, currently the awareness of the importance of the discrete nature of both the matter and the employed computational tools has led to the emergence of a novel epistemological picture. The role of continuous modeling and of homogenization methods is indeed still very important (a useful general references are provided in Refs. [225-227]; recent relevant results are Refs. [136,228-232]; on related numerical schemes see Ref. [233]), but it has a different motivation: namely, continuous models are very powerful for saving computational time. Indeed, one can succeed, by means of homogenization techniques, in:

(1) Capturing all the important features of a given discrete system [234].

(2) Filtering out phenomena occurring at a too small a length scale to be regarded as characteristic of the structure as a whole.

(3) "Cleansing" the system from characteristics that are not interesting for a certain class of applications.

(4) The equations obtained by means of this procedure can be simpler than those coming from discrete modeling, and so they are within reach of existing numerical methods.

This means that the entire passage: (a) discrete microstructure $\rightarrow$ (b) continuous model $\rightarrow$ (c) discrete numerical formulation has the meaning of revealing the essential physical features of the considered structures.

The micro-meso-macro identification, which confers concrete meaning to the mesoscale and to the homogenized models with respect to the micromodel, is characterized by a complex and complementary relationship between classical mechanical models and more sophisticated and rich ones; this point is worth to be discussed in some detail. As long as one does not reach a length scale at which quantum effects are relevant, it is in principle possible to study a structure, at the microlevel, by means of the standard Cauchy continuum model (see Sec. 6, for some observation on classical size-related effects at the nanoscale). The problem of this approach, as already explained, is the enormous computational cost it entails. It is easy, when trying to perform numerical simulations in which the micromodel of a complex structure is directly studied (see below, Fig. 2), that the computational possibilities of the most advanced hardware and software available today are overcome, and that consequently even powerful workstations may be led (and actually were, in the research experience of the 

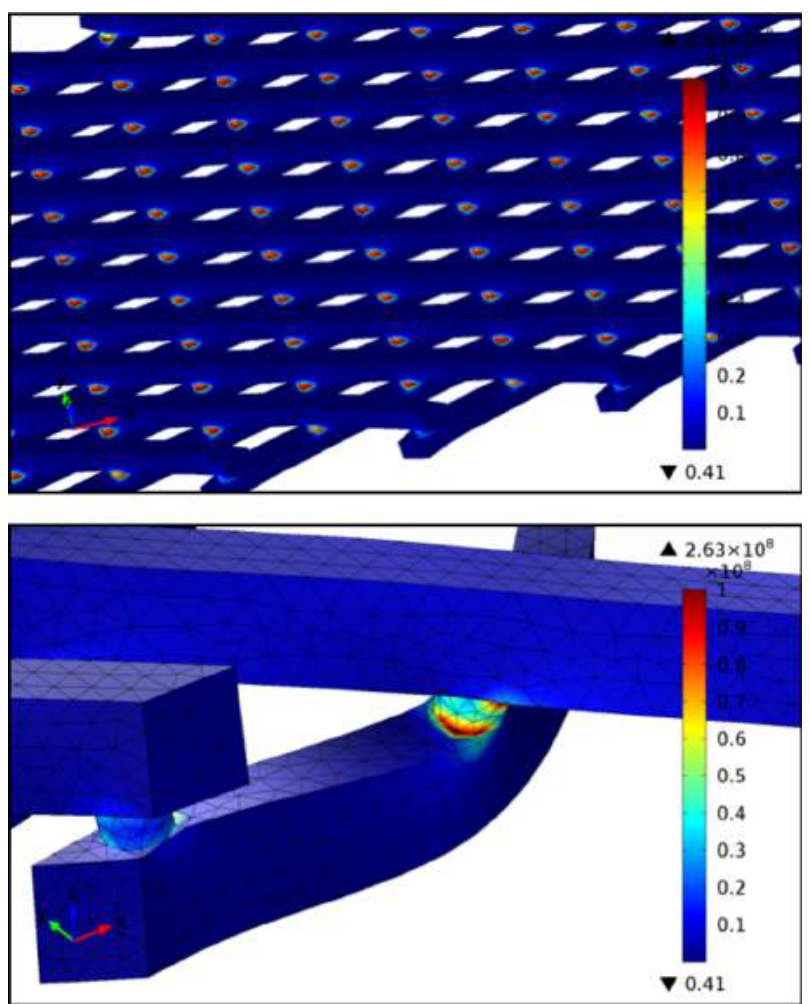

Fig. 2 Three-dimensional simulation for a pantographic structure as studied in Ref. [359]. Top: the deformation energy is stored in the pivots; bottom: the employed mesh is visible (original picture by the authors).

authors!) to a physical breakdown. A mesomodel, in which simpler objects (e.g., beams, chords, Saint-Venant cylinders, etc.) replace Cauchy continua, is in general much less computationally expensive and can therefore be precious once one has successfully established that the simplifying assumptions introduced do not involve the loss of relevant physical information (which is in general not easy). In this process, the generalization/adaptation of existing models, as, for instance, the introduction of a suitable nonlinear model for the beam (see, e.g., Refs. [91,235,236]), is often required. The computational advantage achieved in this way can be of several orders of magnitude, which means that problems requiring computational times of the order of weeks can be dealt with in hours or minutes. Obviously, an even more advantageous result is obtained by identifying the correct homogenized model for the considered system. In this case, usually, one cannot simply adjust existing models, but has to introduce new and more sophisticated generalized continua. Finally, it has to be noted that proving the convergence of the micromodel to the conjectured homogenized one, and even to select the most suitable kind of convergence to be considered, is in general a far from trivial operation [93,237].

5.1 Perspectives for Extension and Generalization of Available Results. Lagrangian mechanics has been formulated for both finite and infinite dimensional systems and is based on stationary principles, exemplified by the principle of virtual work. Because of the intrinsically discrete nature of Turing-von Neumann machines, also infinite dimensional Lagrangian systems must-if they are to produce predictions to be compared with experimental evidence - be approximated by discrete ones. A critical research field concerns the search for discrete simplified Lagrangian systems approximating discrete but more complex ones, without passing through homogenized continuous field models. General results in this context have never been applied to
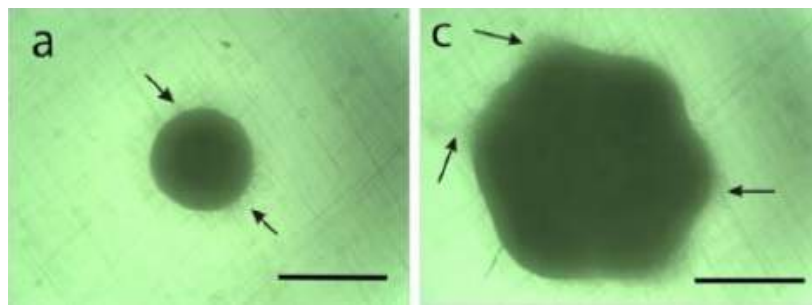

Fig. 3 A prestretched electrospun polyurethane metamaterial used as a scaffold for tissue growth; left: single tissue spheroid attached to the electrospun scaffold; right: seven fused tissue spheroids attached to the scaffold. Arrows indicate the areas of attachment-dependent cell and tissue spreading; scale-bar $300 \mu \mathrm{m}$ (from Ref. [274]; free licence from SAGE webpage ${ }^{2}$ ).
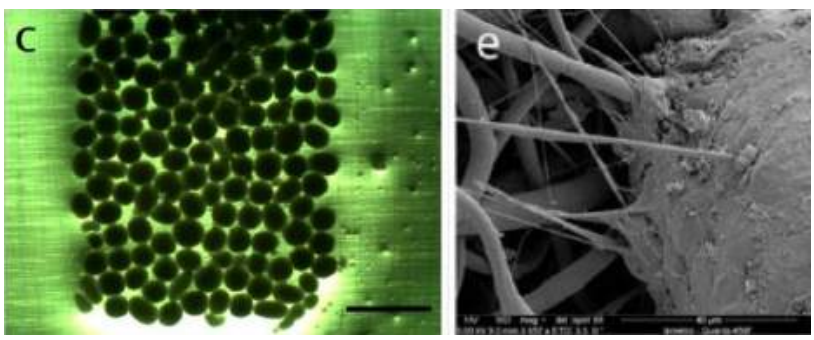

Fig. 4 Left: tissue spheroids adherent to the electrospun scaffold; right: SEM image of the adhesion of tissue spheroids to the electrospun matrix (from Ref. [274]; free licence from SAGE webpage $^{3}$ )

material and structural mechanics and may offer a major opportunity to advance the application of discrete mathematics.

From an historical point of view, it has to be deeply investigated the reason for which the founders of analytical mechanics, i.e., Navier, Poisson, Cauchy, Piola, Boltzmann, and all their successors, even if being strongly persuaded that the "true" ultimate nature of matter was discrete, still wanted to introduce a continuous model for deformable bodies. It could be that this choice was dictated simply by the deeply rooted habit of looking for analytical solutions using the methods of classical mathematical analysis, or by using semi-analytical methods as those developed by means of every kind of series expansion. It cannot be excluded, however, that these pioneers were aware of the importance of continuous models when the global behavior of a structure has to be investigated. The standard classification of PDEs in parabolic, hyperbolic, and elliptic may support such an epistemological point of view. For instance, a set of masses connected by nonlinear springs may exhibit many chaotic and extremely unlikely (or macroscopically irrelevant) kinds of time evolution. However, proving that in the regime of small deformations they are governed by the hyperbolic D'Alembert wave equation allows for a deep understanding of their overall behavior. One of the main expected results of the forthcoming researches is that many more exotic global behaviors will be obtained simply interconnecting elementary structural elements. In particular, the results obtained for 1D systems [135] can be generalized by showing how to synthesize microstructures whose continuous counterparts exhibit "forbidden" frequencies for wave propagation [238], the onset of trapping boundary layers or energy trapping at the microscopic level and consequent enhanced damping $[239,240]$. Exemplifying this multiscale structure is the model for fabrics conceived in Ref. [241], which,

${ }^{2}$ http://www.ncbi.nlm.nih.gov/pmc/articles/PMC4229054/figure/fig3-2041731414 $556561 /$

${ }^{3}$ http://www.ncbi.nlm.nih.gov/pmc/articles/PMC4229054/figure/fig3-2041731414 556561/ 
however, is concerned only with static problems. The most interesting extensions of these researches involve:

(1) The introduction of kinetic effects at the smaller scale.

(2) The extension to 2D (see Ref. [136]) and 3D structures.

(3) The introduction of multiphysics effects via the introduction of suitable transducers, as, for instance, those based on the piezoelectric effect [242-244].

Another field in which new results are needed because of newly arisen technological possibilities is related to the study of instabilities. Indeed, it is easily understood that instabilities in the microstructure of a complex system may imply "macro" effects of various kinds, including phase transitions [245,246] and other kinds of overall behaviors. The study of complex types of instabilities is therefore of crucial importance in order to fully exploit the potential afforded by complex microstructures. In this regard, relevant results are available in the literature concerning both general aspects [247-260] and more specific issues related to the behavior of the microstructure [261-264].

5.2 Experimental Features. As already observed, the emergence of computer-aided manufacturing is having deep consequences for the evolution of Mechanics, which also involve numerical and theoretical developments. Indeed, it can be observed that a very remarkable feature of computer-aided manufacturing is that one can employ the same code (or compatible versions of the same code in different software) for both producing a sample and establishing the topology for performing numerical simulations. This feature has very deep consequences of a methodological and even epistemological nature. The concept of "description of reality through a theoretical model" seems in this case more powerful, as most of the approximate character of the numerical study is sidestepped by the aforementioned identification between the model for numerical investigation and the one for realizing the object.

Concerning experimental work, some specifications have to be made between different kinds of computer-aided manufacturing. Indeed, while $3 \mathrm{D}$ printing allows for the construction of very specific multiscale fabrics (see, e.g., Refs. [140,265,266]) whose quality can be very precisely controlled (at least at the level of $10^{-2} \mathrm{~mm}$ ), the technology of electrospinning allows for the construction of micro- and even nanostructures, but with a much more limited precision (see, e.g., Refs. [267-271]). In this context, the improvement of electrospinning control capability is one of the most interesting problems. It is conceivable to design, for example, better devices which exploit the dependence of surface tension on the curvature of the outer interface of the injected filament [272]. Moreover, a sensitivity analysis to estimate the effect of nano- and micro-imperfections on the global behavior of the considered fabrics would also be of great interest, and increase the already considerable potential that electrospinning techniques have in several fields, including tissue engineering (see Ref. [273]). Concerning these applications, a notable example is the construction of polyurethane biomimetic scaffolds for driving the growth of cell tissues. In Ref. [274], specifically, a thin prestretched elastic polyurethane electrospun scaffold has been shown to serve as a supporting template for rapid biofabrication of thick tissue-engineered constructs (see Figs. 3 and 4).

Besides technical difficulties in achieving the desired degree of accuracy at the nanoscale, deeper problems connected with nanosized objects concern the presence of size-related effects which are not observable at macro- and microscale. Among them there are problems which depend on the intrinsic nature of the physics laws (classical or quantum ones) governing phenomena at a given length scale; in addition, there are also specific size-related effects which are completely captured even by a classical approach, and which start to play a relevant role, as the length scale decreases, well before quantum mechanics is required. Given the importance of these last effects for the experimental and theoretical study of metamaterials and for the exploitation of their characteristics, an overview of them is provided in Sec. 6.

We conclude this section by remarking that computer-aided manufacturing techniques and other advanced manufacturing procedures are not the only ones able to produce new interesting metamaterials. Indeed, the research is by any means confined to them, and many interesting cases of metamaterials exhibiting new and promising behaviors are indeed being realized through

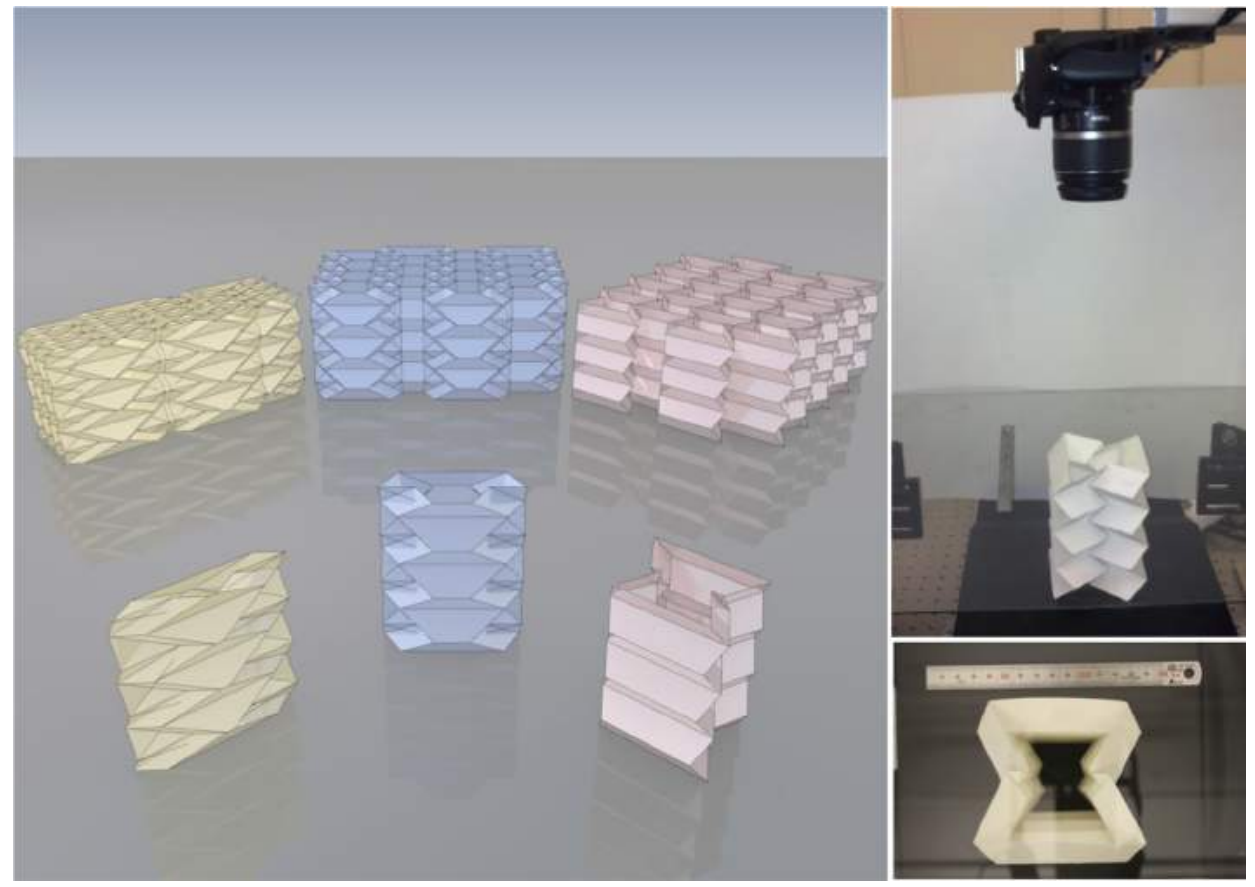

Fig. 5 Handicraft metamaterial exhibiting interesting mechanical properties (high damping, negative stiffness, snap-through, etc.): Tachi-Miura polyhedron realized by means of origami structures made of paper as studied in Ref. [275]. Left: digital image of the prototypes; right: photo of the top of the prototype (original pictures by the authors). 

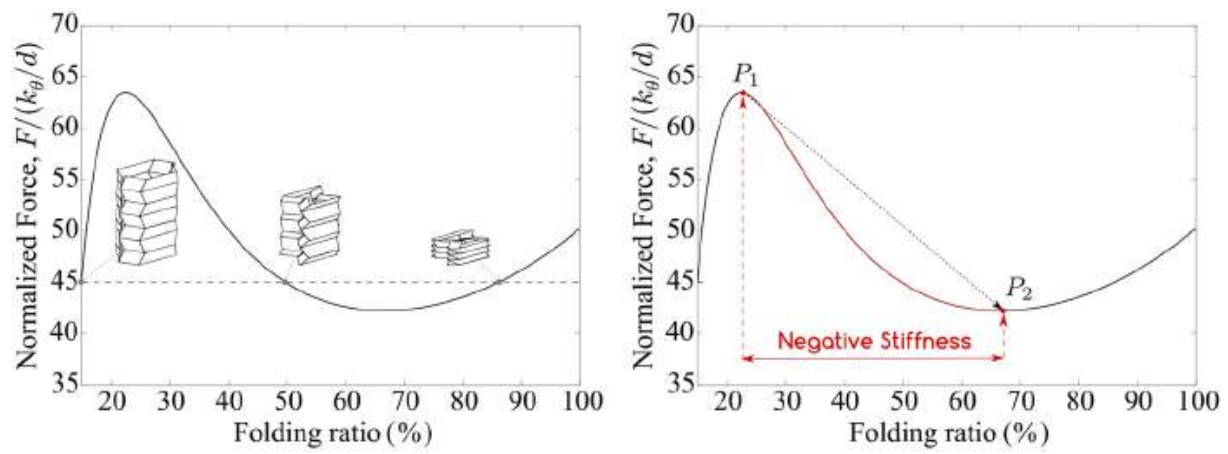

Fig. 6 Left: three different configurations of the papermade Tachi-Miura polyhedron (studied in Ref. [275]) under the same normalized force; right: force-folding ratio relationship and snap-through response (original rendering of pictures provided by the authors)
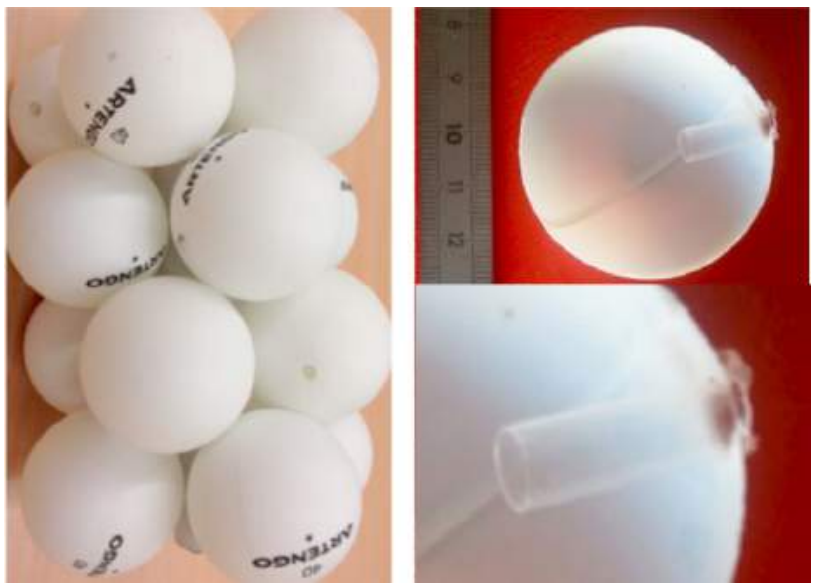

Fig. 7 Another example of handicraft metamaterial: hollow plastic spheres (138 $\mathrm{mm}$ high) with a central impervious cylinder studied in Ref. [276]. Spheres might be impervious hollow spheres, or resonators, or both (see Table 1 in the reference paper for details). The interspheres space might be occupied either by air or filled by a granular medium. Left: geometry of the prototype; middle: a prototype; right: cut of the two types of Helmholtz resonators (original pictures by Professor Claude Boutin).

ordinary industrial procedures, and even (at least in the prototyping phase) through handicraft methods. An interesting example of this kind is provided in Ref. [275], where a Tachi-Miura polyhedron made of paper is realized and studied (see Fig. 5). The authors measured cross-sectional area of the structure and studied how mechanical properties depend on it. In Fig. 6-right panel, the normalized force (i.e., the applied force divided by a density of torsional stiffness) is represented versus the folding ratio, and the loading and unloading behaviors show that the system can achieve hysteresis effect under dynamical circumstances, which can be exploited for building structures with promising damping properties. In Fig. 6-left panel, three different configurations reached by the system under the same value of the normalized force, having significantly different folding ratio, are graphically shown. Another interesting case of handicraft metamaterial is the one realized and studied by Boutin and Becot [276]. The authors investigate theoretically and experimentally the acoustics of gassaturated rigid porous media with inner resonance effects. By realizing a prototype made by cutting hollow plastic spheres and packing them with an approximately cubic geometry (see Fig. 7), they confirmed experimentally that the resonators essentially modify the effective bulk modulus of the medium inducing strong velocity dispersion and high attenuation in the frequency range of

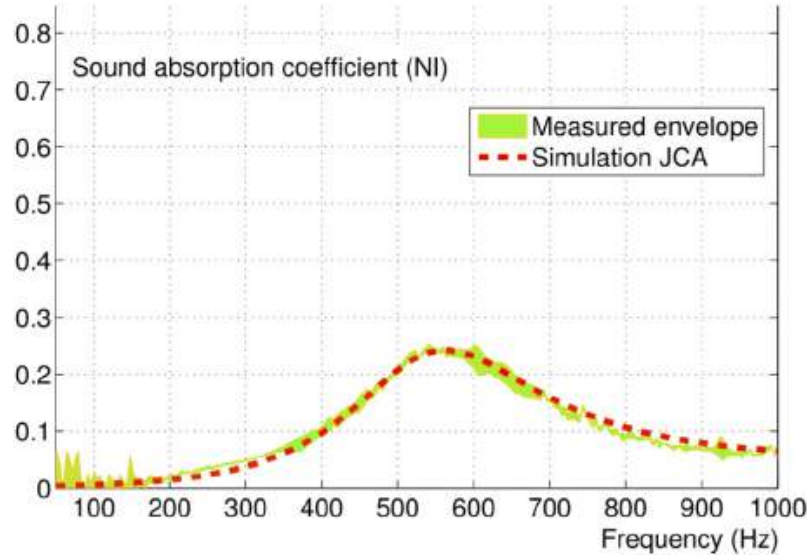

Fig. 8 Sound absorption coefficient at ambient condition of temperature and pressure for the system studied in Ref. [276] and represented in Fig. 7. Measurement is represented by the thick line and simulation by the dashed one (original picture by Professor Claude Boutin).

the theoretical band gaps. In Fig. 8, sound absorption coefficient of the sphere packing shown in Fig. 7 can be seen at ambient condition of temperature and pressure. Measurement is represented by the thick line and simulation by the dashed one. A very similar kind of investigation concerning the bulk effects of microstructure resonance is carried in Ref. [277] (for related researches, see also Refs. [278-281]) with respect to a structure constituted by a shaking table equipped with aluminum sheets acting as resonators (see Fig. 9). The effect on resonance of the addition of 1 and 37 sheets is represented in Fig. 10; as one can see, very sharp changes in the resonance properties of the structure result from the addition of 37 resonators. This last research was a particular case of a more general research line involving locally resonant mechanical metamaterials (see, for instance, Refs. [282,283]).

\section{Micro- and Nanostructured Materials Presenting Surface-Related Effects}

A case in which microstructure can affect significantly the behavior of a mechanical system is the presence of surface- and interface-related effects (see, for instance, Refs. [284,285]). At the moment, we do not have yet a general and comprehensive theoretical framework which is able to cover this topic in a satisfactory way, and a big amount of effort by researchers from different fields is being made to achieve it, or at least to add some pieces to the puzzle. We will try to briefly illustrate where the line separating already understood phenomena and open problems lies. 

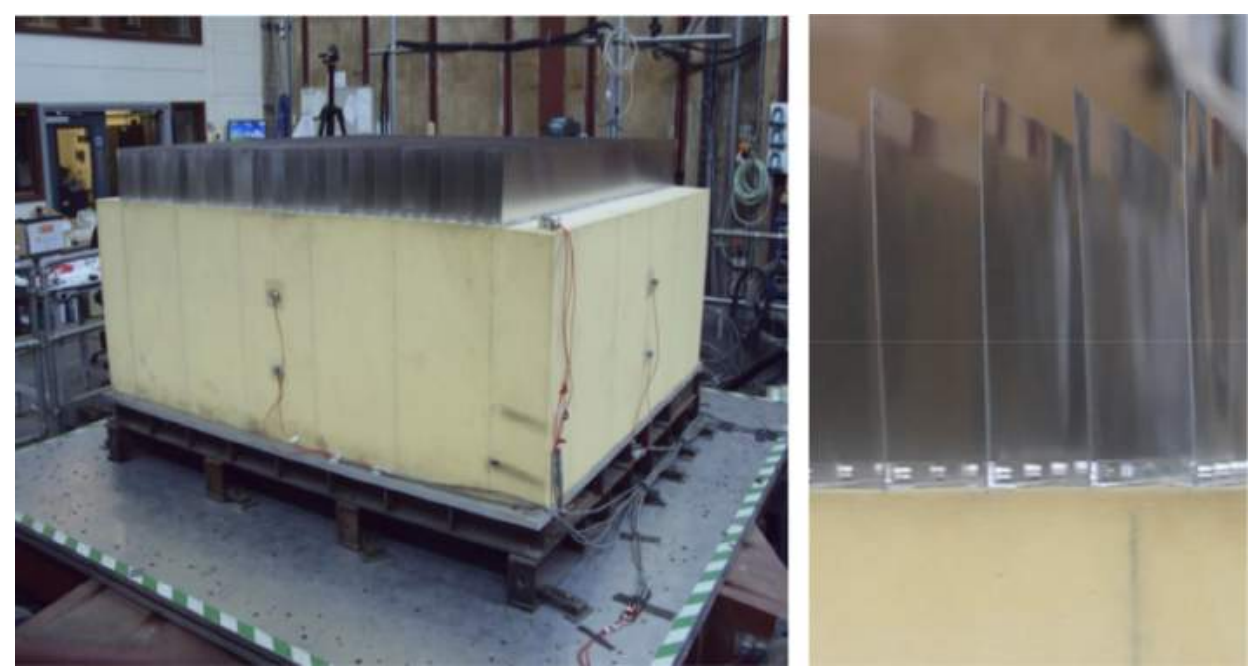

Fig. 9 Left: shaking table (Bristol Laboratory for Advanced Dynamics Engineering) equipped with aluminum sheets acting as resonators as studied in Ref. [277]; right: zoom on the sheets (original pictures by Professor Claude Boutin)
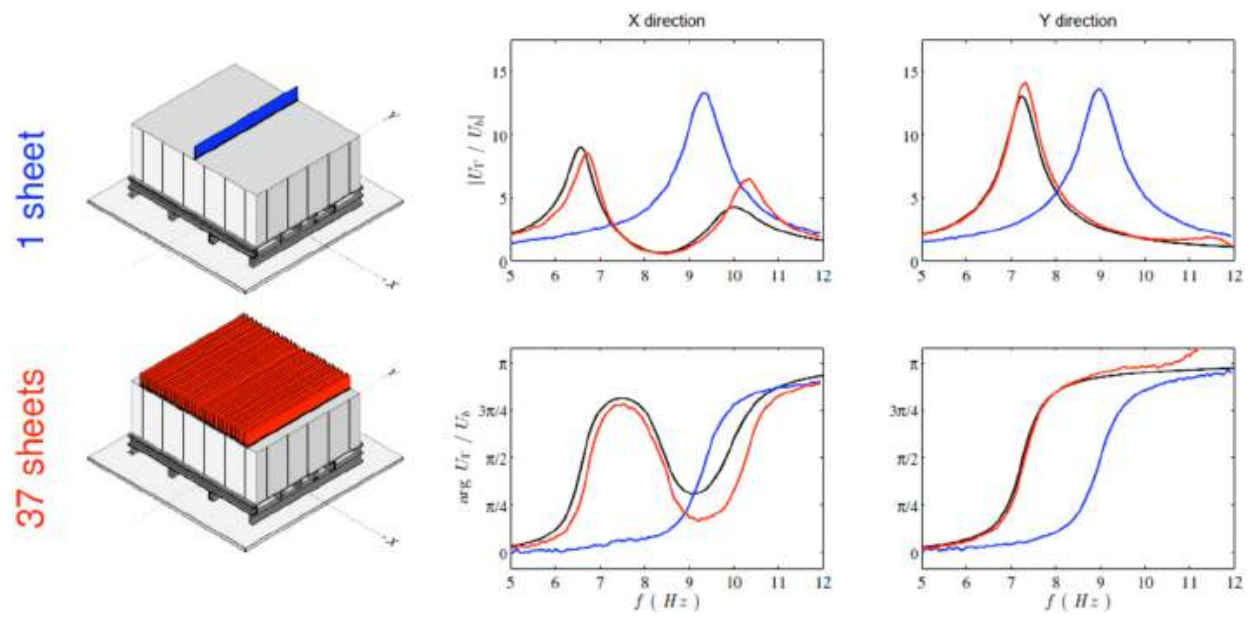

Fig. 10 Changes in spectrum surface/table for the system studied in Ref. [277] and shown in Fig. 9. The curve for one resonator is very close to usual layer's resonance; the curve corresponding to 37 resonators shows drastic changes in layer's resonance in $x$ resonant direction and usual resonance peak in $y$ inert direction; in black: standard impedance analysis is also shown; $U_{\Gamma}$ and $U_{b}$ are, respectively, the displacements of the material points belonging to the upper surface and to the base of the sample (original picture by Prof. Claude Boutin).

The general concept is that, in the presence of complex microor nanostructures, surface effects are the most relevant factor in determining size-related behaviors. The development of microand nanotechnology is indeed making even more acute the need for new theoretical developments. There are several examples of new materials which try to exploit the specific characteristics that surface-related effects can have in the presence of complex microstructures. In the literature (see, e.g., Ref. [286]), a distinction is made between "extrinsic" and "intrinsic" size effects, i.e., the dependence of the bulk properties, respectively, on the size of a sample or on the micro- and nanostructure. Examples of the two types are provided, respectively, in Refs. [287-291,292,293].

Concerning the geometry of the surfaces, we can start by mentioning the simplest case, i.e., the so-called "perfect" surfaces. These are the ones that can be described by the tools of standard differential geometry with the simple addition of some special physical properties (see, for example, the surface of the nanocrystals and nanotubes made of $\mathrm{ZnO}$ shown in Fig. 11 and studied in Ref. [294]). This, however, is just a very special case. There are indeed several cases of largely irregular geometry even in the presence a microstructure constituted by nanotubes or nanocrystals, since their spatial configuration can be very far from uniform, as shown in Fig. 12. Materials with this type of surfaces can be employed for many applications, including the production of sensors, actuators, and other elements of micro- and nanoelectromechanical systems (see, for example, Refs. [295-301]). For this type of surfaces, it is completely pointless to aim at a detailed mathematical description, and instead suitable averaged models have to be developed; this is in the opinion of the authors of one of the most promising research directions. An application which is important for the development of energetically advantageous solar cells is provided by the so-called Black Silicon (see Ref. [301] and Fig. 13); another example of results having application to photovoltaic technology is the theory of layered plates and shells provided in Ref. [302]. Self-cleaning and bactericide coatings provide other examples of highly irregular surfaces exploited to obtain specific properties (see, e.g., Refs. [303-313]).

The concept of surface tension for solids, introduced by Gibbs [314], is still an active research field (for a coverage of recent 


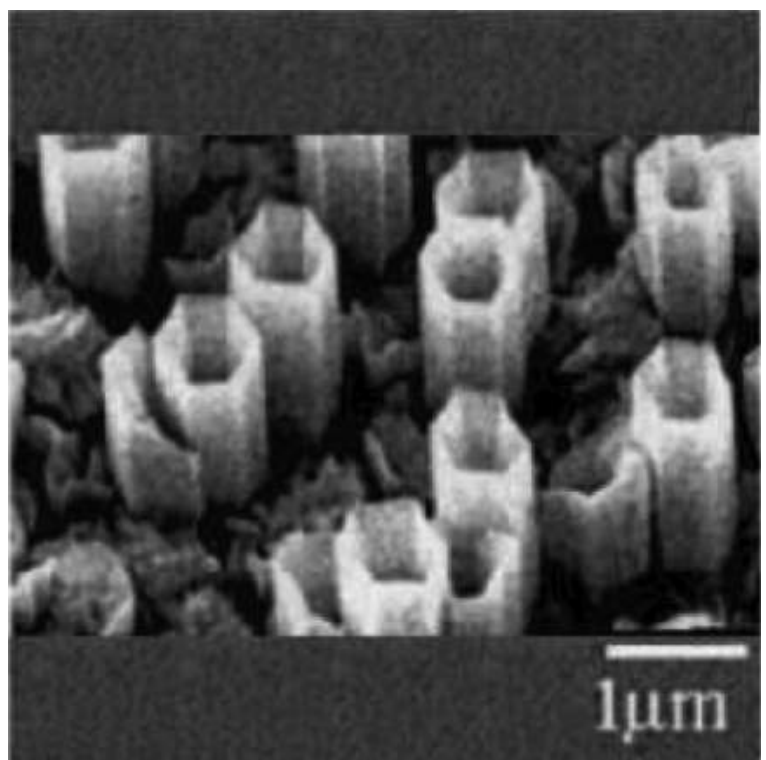

Fig. $11 \mathrm{ZnO}$ crystal and $\mathrm{ZnO}$ nanotubes (Reproduced with permission from Özgür et al. [294]. Copyright 2005 by AIP.)

literature, the reader can see Refs. [315,316] and the works there cited). Gurtin and Murdoch introduced in Refs. [317,318] a model in which a nonlinear elastic solid is equipped with a prestressed membrane on the surface to account for surface tension. This model found applications in micro- and nanomechanics (see, e.g., Refs. [319-321]), and in particular proved capable of describing size-related differences in mechanical properties, as
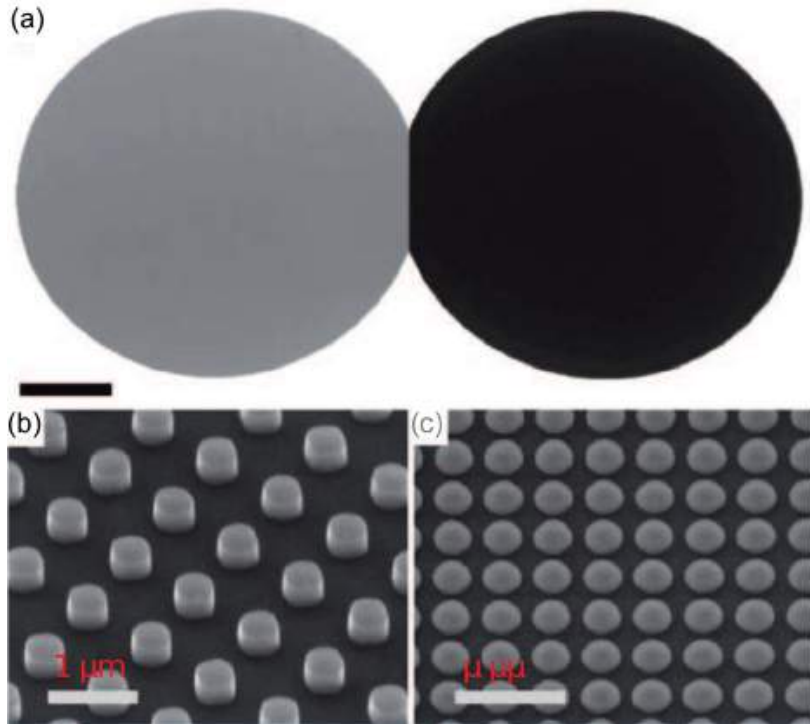

Fig. 13 "Black silicon" for solar cells (Reproduced with permission from Spinelli et al. [301]. Copyright 2012 by Nature Publishing Group.)

observed, for instance, in Ref. [322]. The importance of this model can also be appreciated considering that many generalizations were proposed for it, for instance, adding bending stiffness for the external membrane and accounting for thermoelasticity or fracture (see Refs. [323-328]). In this framework, it is of course very useful to provide solutions to initial value problems (IVPs)
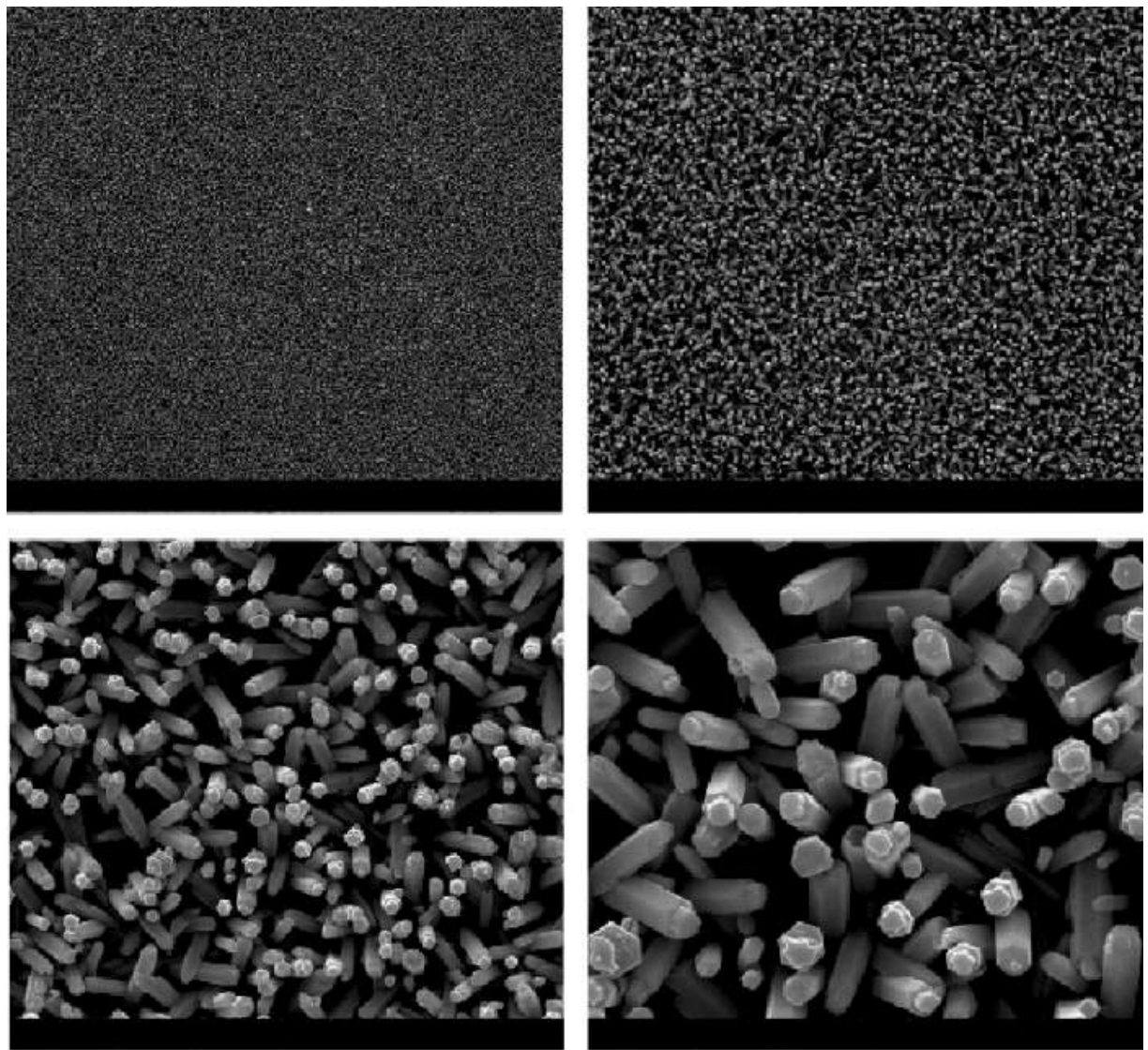

Fig. 12 ZnO nanoarray (respectively, $300 \times, 1200 \times, 5000 \times$, and 10,000 $\times$ from top left to bottom right) (Reproduced with permission from Ma et al. [298]. Copyright 2008 by Elsevier.) 
and boundary value problems (BVPs) which are met in surface elasticity; related results are provided in Refs. [20,21,329,330].

Surface elasticity influences the properties of the material, as shown in Refs. [319,320]. A remarkable theoretical result is that, in linear surface elasticity, the presence of surface stresses leads to a stiffening of the material (see, for example, Refs. [21,331-335]). This general result helps understanding the fact that, in fracture mechanics, the presence of surface reinforcements can change the behavior of solutions in proximity of cracks, holes, and other kind of singularities, as it was shown in Refs. [327,328].

To complete the picture concerning surface stresses and effects, we add a list of other related topics developed in recent literature:

(1) The influence of surface stresses on the free vibrations of materials is investigated in Refs. [336-340].

(2) The finite deformations of elastic solids in the Gurtin-Murdoch model is studied in Refs. [341-344].

(3) The study of BVPs in case of linear elasticity with surface stresses is performed in Refs. [20,21,24,329,330].

(4) Numerical study (based on FEM) of bodies with surface stresses is provided in Refs. [345-347].

(5) Ab initio methods and other atomistic simulations are covered in Refs. [348-351].

(6) Surface energy introduced by means of the evaluation of the excess of bulk energy close to the surface is investigated in Ref. [352].

(7) Models of higher gradient continua capable to include surface stresses are presented in Refs. [315,353-356].

\section{Example: Pantographic Structures}

As a model case of a structure which can be 3D printed and studied by means of the approaches proposed in Sec. 3, we will briefly describe pantographic sheets. By this, we mean a structure constituted by long fibers, which can be modeled as Euler or Timoshenko beams, inextensible chords, or in other ways according to the particular application at hand (see Fig. 1). The fibers form parallel arrays orthogonal to each other, and each fiber belonging to an array is interconnected via internal pivots to all the fibers of the other array (see Refs. [190,240]).

This system appears rather simple in its geometry and in the mechanics of its basic substructure, but nevertheless is capable of very rich macroscopic behavior which poses great challenges to its theoretical characterization, due primarily to: (i) the need to account for special constraints, such as inextensibility and (ii) the presence of "floppy modes"; i.e., macrodeformations to which no strain energy is associated. Moreover, it is clearly of a multiscale nature, as it is characterized by four different length scales: the diameter of the fibers, the spacing between the fibers, the distance between the closest pivots, and the size of the pivots.

This structure can have a very advantageous strength/weight ratio, and it is experimentally proved that it exhibits a particularly safe behavior in fracture [357], since it is capable of sustaining load in a stable fashion long after the inception of fracture: the part of energy absorbed by the system between the end of the elastic regime and the ultimate failure is comparable to that stored as elastic deformation energy. These features make it a very promising candidate for applications in the aeronautical and aerospace industries.

A basic version of this structure has already been printed and experimentally studied in recent research activity [357-359]; in Fig. 1 (top) the result of a so-called "bias test" is shown. One can clearly observe the presence of different "phases"; i.e., regions in which the shear deformation is more or less constant, with almost vanishing bending of the fibers, separated by thin layers in which bending is concentrated. This qualitative behavior was accurately reproduced by introducing a continuum model (Fig. 1 (bottom), where shear deformation is represented on the vertical axis). We remark that this picture is relative to a continuum simulation, and that the curves represent sets of material points which are straight lines in the reference configuration. For the continuum model, a placement $\mathbf{r}$ can be considered which is a vector function defined over the planar domain corresponding to the reference configuration of the sample, taking values in $\mathbb{R}^{3}$

$$
\mathbf{r}=X_{\alpha} \boldsymbol{e}_{\alpha}+u_{i}\left(X_{\alpha}\right) \boldsymbol{e}_{i}
$$

with Latin indexes ranging from 1 to 3 and Greek indexes from 1 to 2 ; the $u_{i}$ are the three components of displacement.

The strain-energy function of the model is

$$
W=W_{1}\left(C_{\alpha \beta}\right)+W_{2}
$$

where

$$
\begin{gathered}
C_{\alpha \beta}=r_{i, \alpha} r_{i, \beta} \quad E_{\alpha \beta}=\frac{1}{2}\left(C_{\alpha \beta}-\delta_{\alpha \beta}\right) \\
W_{1}=\frac{1}{2} Y_{L}\left(L_{\alpha} L_{\beta} E_{\alpha \beta}\right)^{2}+\frac{1}{2} Y_{M}\left(M_{\alpha} M_{\beta} E_{\alpha \beta}\right)^{2}+\mu\left(L_{\alpha} M_{\beta} E_{\alpha \beta}\right)^{2} \\
W_{2}=\frac{1}{2} A_{L}\left|L_{\alpha} L_{\beta} \boldsymbol{r}_{, \alpha \beta}\right|^{2}+\frac{1}{2} A_{M}\left|M_{\alpha} M_{\beta} \mathbf{r}_{, \alpha \beta}\right|^{2}+\frac{1}{2} A_{T}\left|L_{\alpha} M_{\beta} \mathbf{r}_{, \alpha \beta}\right|^{2}
\end{gathered}
$$

and

$$
\begin{aligned}
\boldsymbol{L} & =\frac{1}{\sqrt{2}}\left(\hat{e}_{1}+\hat{e}_{2}\right) \\
\boldsymbol{M} & =\frac{1}{\sqrt{2}}\left(\hat{e}_{1}-\hat{e}_{2}\right)
\end{aligned}
$$

This is in many aspects the simplest choice for the constitutive model, as (for instance) the same stiffness coefficient is assumed for normal and geodesic bending, and yet it is able to reproduce exceptionally well the experimental evidence. We can expect that subsequent refinement of the model will lead to even better quantitative predictions.

The continuum model was conceived to account for energy related to microstructural in-plane bending, which manifests itself macroscopically as geodesic curvature. It is not possible to model the response to this kind of deformation without introducing a second gradient contribution to the energy density. This is clearly established by the very good fidelity exhibited by the numerical simulations based on the foregoing theoretical model with respect to the patterns observed in the actual test.

In addition to the simulations based on the continuum model, mesoscale simulations based on an averaged model in which the energy (thought as dependent only on the angles between the fibers) is concentrated in the nodes of a lattice were performed (see Ref. [359]). In Figs. 14 and 15, the angular variation between

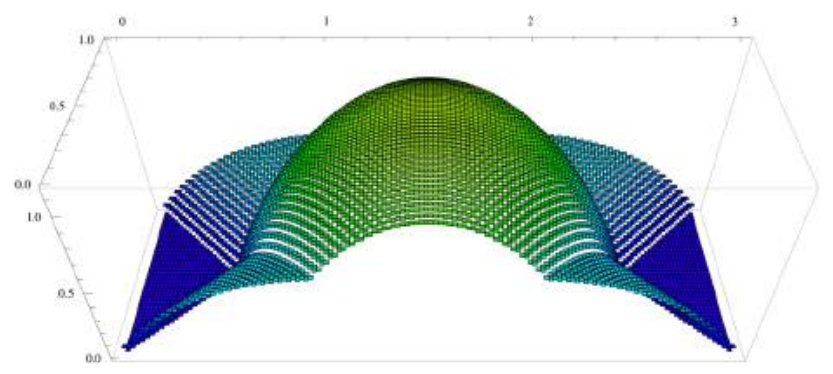

Fig. 14 Deformation energy for a second gradient lattice mesomodel of a sheet with inextensible fibers, with an imposed elongation of $60 \%$, as studied in Ref. [359] (original picture by the authors) 


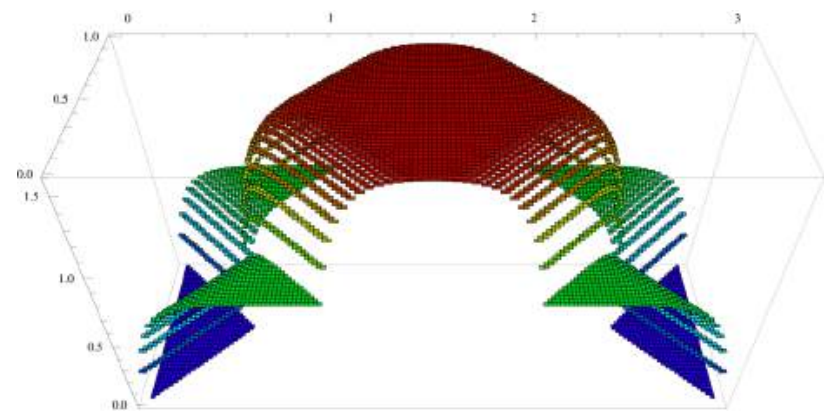

Fig. 15 Deformation energy for a mixed first and second gradient lattice mesomodel of a sheet with inextensible fibers, with an imposed elongation of $\mathbf{8 0 \%}$, as studied in Ref. [359] (original picture by the authors)

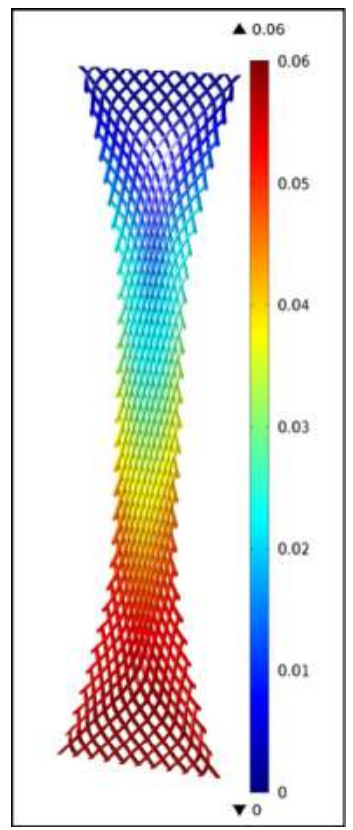

Fig. 16 Three-dimensional simulation for a pantographic structure in traction as studied in Ref. [359] (original picture by the authors)

the inextensible fibers with respect to the undeformed configuration is plotted, resulting in well visible boundary layers and undeformed triangular regions close to the shortest sides. Finally, large-scale simulations of the actual 3D structure were also conduced (see Ref. [358]; this is a particular case of the general feature that was already discussed before, i.e., with 3D-printing, one can employ the same code for both producing the sample and establishing the topology for performing numerical simulations. It is worth noting, recalling what was mentioned in Sec. 5, that the previous mesoscale simulations required a computation time approximately $10^{4}$ times smaller than these last ones.

In Fig. 16, we show 3D numerical simulations based on the same code used for manufacturing the object shown in the previous figure; a numerical bias test is shown (norm of absolute displacement is plotted by means of a color map). In Fig. 2-top, the strain-energy density is shown in a more restricted region, and one can observe that almost all the energy is stored in the pivots as torsional energy. In Fig. 2-bottom, a sharper resolution is shown, which is particularly fine at the pivots.

This 3D model represents the micromodel of the considered structure, while its eventual homogenization by means of a

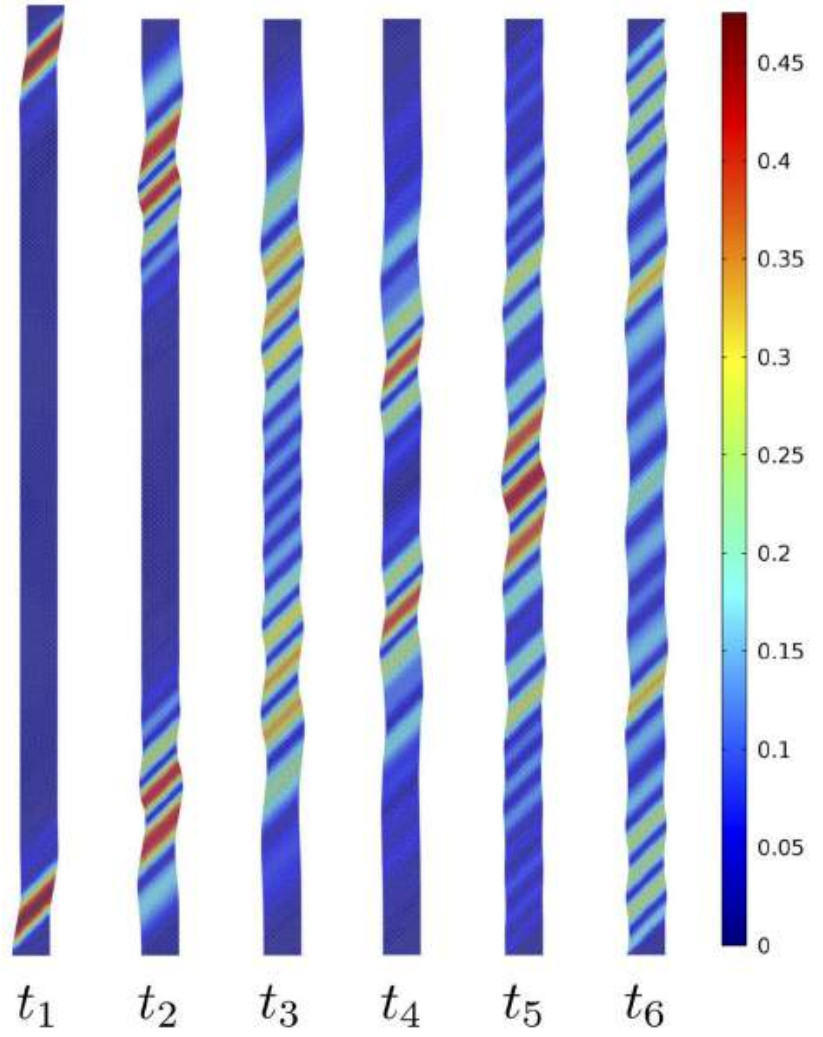

Fig. 17 Waves traveling in opposite directions in a pantographic structure (Reproduced with permission from Madeo et al. [240]. Copyright 2014 by Proceedings of the Estonian Academy of Sciences.)

suitable continuum model will represent the "macro" approach. Between them, a mesomodel in which the Euler beam model will account for the description of the fibers can also be introduced.

Concerning the theoretical formulation of the problem, we confine ourselves to an outline of some relevant concepts for the purpose of illustrating the difficulties that can arise. For example, the introduction of fiber inextensibility entails the presence, in the Lagrangian of the system, of terms expressed by means of nonlocal (integral) operators representing the constraint [193], leading to mathematical problems that are much more complex than those associated with local constraints. For example, in a test with a diagonal displacement at $45 \mathrm{deg}$ with respect to the sides of a rectangular sample, with boundary displacements $u_{01}$ and $u_{02}$, one has the following integral conditions in case of inextensible flexural beams with internal hinges [192]:

$$
\left\{\begin{array}{l}
\int_{1}^{3}\left(\cos \left(\vartheta_{1}(\eta)\right)+\sin \left(\vartheta_{2}(\eta)\right)\right) d \eta=2+u_{01} \\
\int_{1}^{3}\left(\cos \left(\vartheta_{2}(\eta)\right)+\sin \left(\vartheta_{1}(\eta)\right)\right) d \eta=2+u_{02}
\end{array}\right.
$$

where $\eta$ is the curvilinear abscissa along the fibers in the reference configuration, $\vartheta_{i}$ are the kinematical descriptors representing the angular variation of the two families of fibers with respect to the reference configuration, and the value 2 is due to the shape ratio (3:1) of the sample (for details, see Ref. [189]). More complicated integral conditions will appear in the resulting evolution equations in the case of a more general imposed displacement.

The dynamics of such systems is expected to be very rich and to exhibit unusual features, including the presence of nonstandard interaction between opposing waves (Fig. 17) and energy entrapment by means of filters constituted by an array of springs 


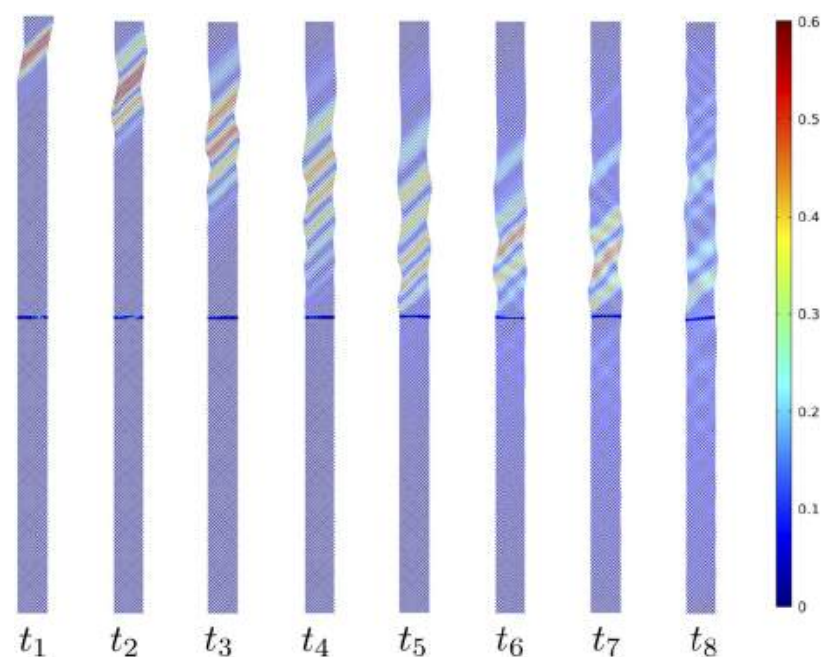

Fig. 18 Damping of a wave by means of an array of vertical springs in a pantographic structure (Reproduced with permission from Madeo et al. [240]. Copyright 2014 by Proceedings of the Estonian Academy of Sciences.)

(Fig. 18) [190]. Selecting different stiffnesses for the two families of parallel beams, the system can yield different dispersion coefficients in different directions. The homogenized continuum theory, to be developed, must be rich enough to account for this kind of behavior, which, together with the exploitation of possible soft-modes, can aid in the realization of acoustic (cloaking) applications.

Further, the foregoing continuum model may be extended to accommodate three-dimensional deformations of the elastic lattice in space. To this end, additional terms are included in the strainenergy function $W$ of the model to account for surface flexure and twist. In such a deformation, we have (see Eq. (4))

$$
\begin{aligned}
L_{\alpha} L_{\beta} \mathbf{r}_{, \alpha \beta} & =\mathbf{g}_{l}+K_{L} \mathbf{n}, \quad M_{\alpha} M_{\beta} \mathbf{r}_{, \alpha \beta}=\mathbf{g}_{m}+K_{M} \mathbf{n} \\
L_{\alpha} M_{\beta} \mathbf{r}_{, \alpha \beta} & =\boldsymbol{\Gamma}+T \mathbf{n}
\end{aligned}
$$

where $\mathbf{g}_{l, m}$ and $\boldsymbol{\Gamma}$ account for geodesic bending in the tangent plane of the deformed surfaces, as before, and $\boldsymbol{n}$ is the (variable) unit normal to the evolving deformed curved surface. The variables $K_{L, M}$ and $T$ are the normal curvatures of the embedded fibers and the twist induced by the bending of the surface in three-space.
To help understanding of how these effects should be manifested in the constitutive theory, the strain-energy function may be nondimensionalized by introducing a local length scale. Candidates for this are the thickness of the actual sheet represented by our surface model, the characteristic spacing of the internal pivot points of the actual pantographic lattice or the widths of the constituent fibers. If any of these is used as the length scale, then in typical applications the nondimensionalized vectors $\mathbf{g}_{l}, \mathbf{g}_{m}$ and $\boldsymbol{\Gamma}$ are small enough that the dependence of the strain energy on them is quadratic at leading order, provided that the associated couple stresses and bending/twisting moments vanish when the fibers are straight and untwisted. A simple strain-energy function of this type, incorporating the orthotropic symmetry conferred by the initial fiber geometry, is

$$
\begin{aligned}
W= & w(\lambda, \mu, J) \\
& +\frac{1}{2}\left(A_{l}\left|\mathbf{g}_{l}\right|^{2}+A_{m}\left|\mathbf{g}_{m}\right|^{2}+A_{\Gamma}|\boldsymbol{\Gamma}|^{2}+k_{L} K_{L}^{2}+k_{M} K_{M}^{2}+k_{T} T^{2}\right)
\end{aligned}
$$

where the coefficients $A_{l, m, \Gamma}$ and $k_{L, M, T}$ are constants; this form is assumed for the sake of definiteness and tractability. Other forms are, of course, possible. Here, we take $A_{l, m, \Gamma}$ and $k_{L, M, T}$ to be strictly positive and observe that the part of the energy depending on the second gradient $\nabla \nabla \boldsymbol{r}$ is then nonnegative, vanishing if and only if $\mathbf{g}_{l}, \mathbf{g}_{m}, \boldsymbol{\Gamma}, K_{L}, K_{M}$ and $T$ all vanish simultaneously. It is thus a convex function of $\nabla \nabla \mathbf{r}$, which is enough to secure the existence of energy-minimizing deformations in conservative boundary-value problems via the direct method of the calculus of variations [360]. The resulting model is therefore ideally suited to finite-element analysis.

The constitutive sensitivity to the geodesic and normal curvatures is easily understood in terms of the mechanics of the constituent fibers. In particular, fibers are expected to offer resistance to any mode of bending, be it of the geodesic type or the type induced by surface flexure. Regarding fiber twist, in the present model this is determined by the twist of the surface because of the connectivity of the pantographic lattice substructure. Specifically, both families of intersecting fibers of the lattice are assumed to be pivoted about the current surface normal. This constraint implies that fiber twist is controlled entirely by surface geometry and is therefore not an independent kinematic variable [213].

For the strain-dependent function $w$, we may adopt

$$
w(\lambda, \mu, J)=\frac{1}{2}\left(E_{L} \varepsilon_{L}^{2}+E_{M} \varepsilon_{M}^{2}\right)-G(\ln J+1-J)
$$
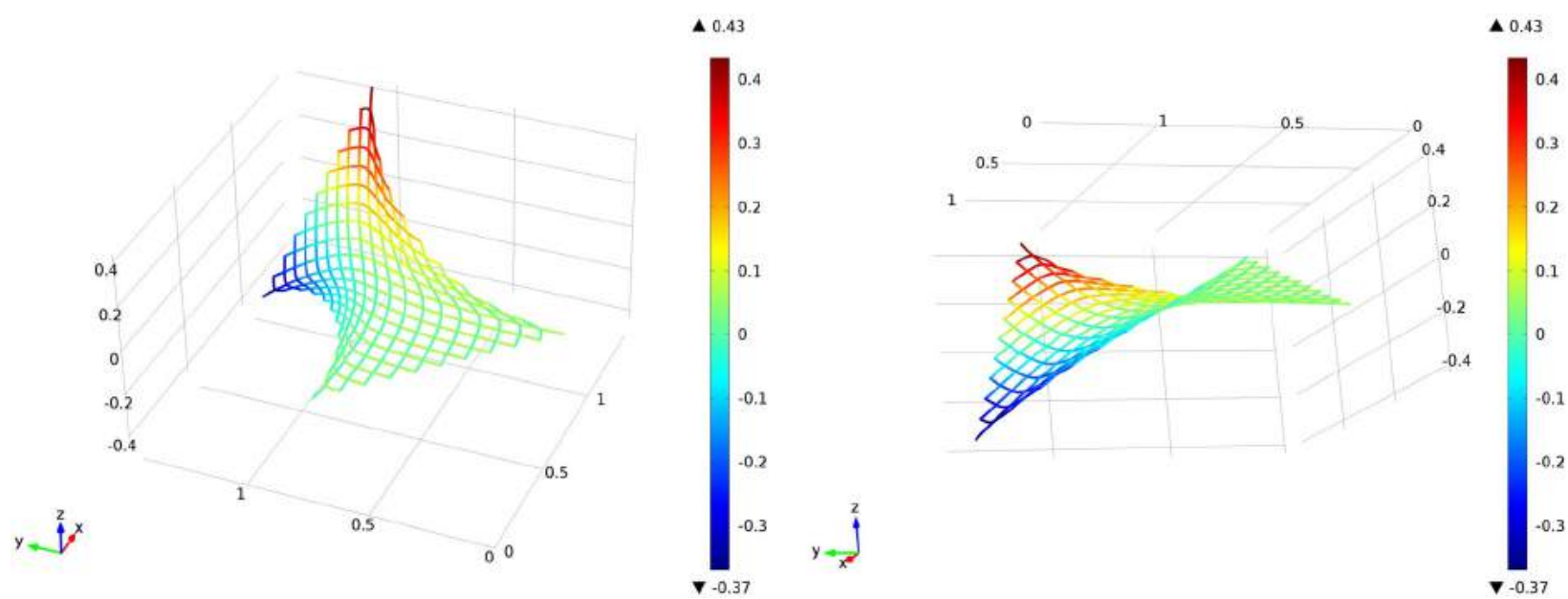

Fig. 19 Out-of-plane twisting of a squared pantographic sheet as studied in Ref. [358]. The picture is relative to a continuum simulation, and that the curves represent sets of material points which are straight lines in the reference configuration (original picture by the authors). 

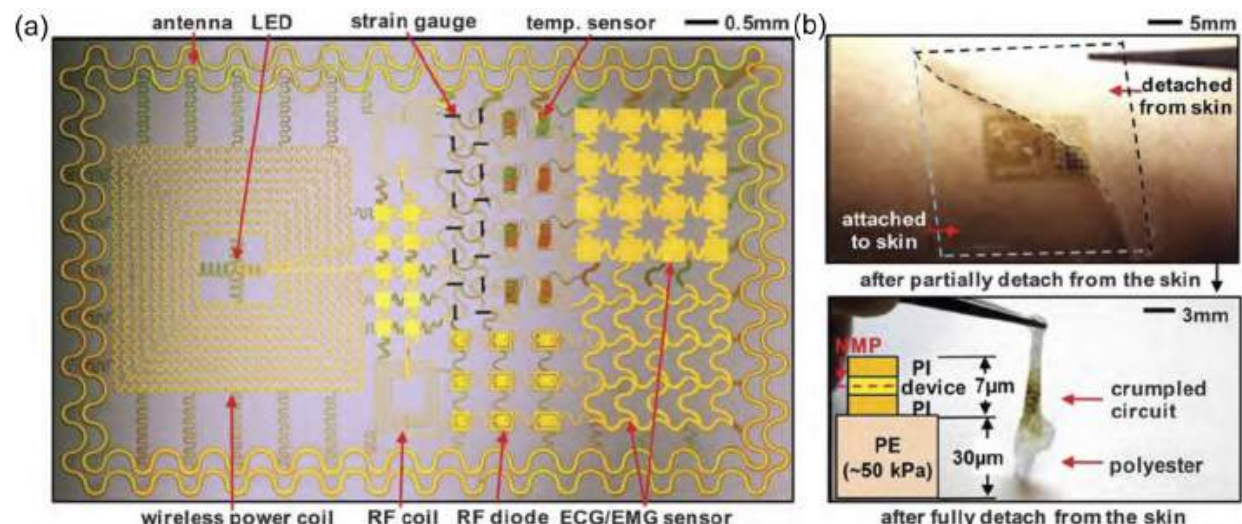

Fig. 20 Epidermal flexible plate (Reproduced with permission from Kim et al. [361]. Copyright 2011 by AAAS.)

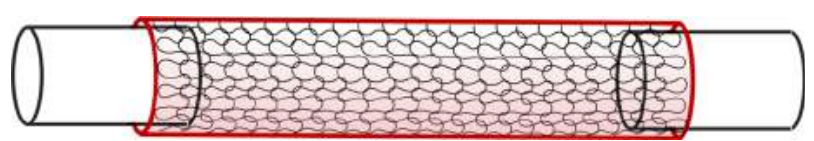

Fig. 21 An architectured material employed for a vascular implant made of $\mathrm{NiTi}$ knitted fabric and inserted in a silicone elastomer (original rendering of a photo from Ref. [369])

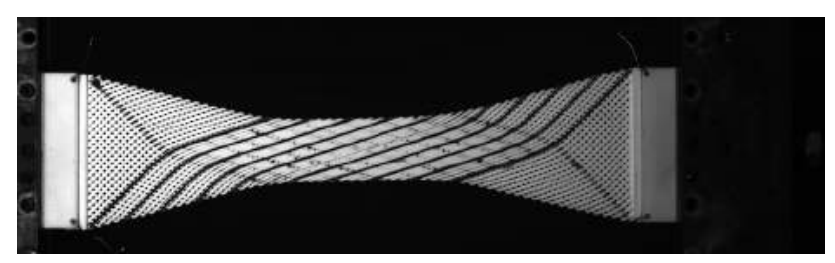

Fig. 22 A pantographic sheet under extensional bias test as studied in Ref. [358]: a concept for a new lightweight, extremely resistant and safe in failure architectured material (original picture by the authors) where

$$
\varepsilon_{L}=\frac{1}{2}\left(\lambda^{2}-1\right), \quad \varepsilon_{M}=\frac{1}{2}\left(\mu^{2}-1\right)
$$

are the extensional fiber strains, and $E_{L, M}$ and $G$ are the positive constants. This energy does not include a term proportional to $\varepsilon_{L} \varepsilon_{M}$ and therefore does not accommodate a Poisson effect with respect to the fiber axes. Poisson effects are generally nonnegligible in woven fabrics due to fiber crimping and decrimping [193,213], but this mechanism is absent in pantographic lattices. Finally, the term involving $J$ penalizes fiber collapse $(J \rightarrow 0)$ by requiring unbounded growth of the associated energy.

Figure 19 illustrates a simulation based on this theory in which one edge of the lattice is fixed and the opposite end undergoes a relative displacement and twist in three dimensions (we again remark that the picture represents a $2 \mathrm{D}$ continuum simulation; see the caption). The effect is to introduce substantial bending and twisting of the lattice without disturbing the aforementioned phase segregation pattern. This generalization of the model is important in providing a capability to model the potentially complex threedimensional deformations of real lattice substructures. It may be further extended through refinement of the constitutive equations and the introduction of kinetic effects to capture wave propagation and structural vibrational modes. The latter are expected to be

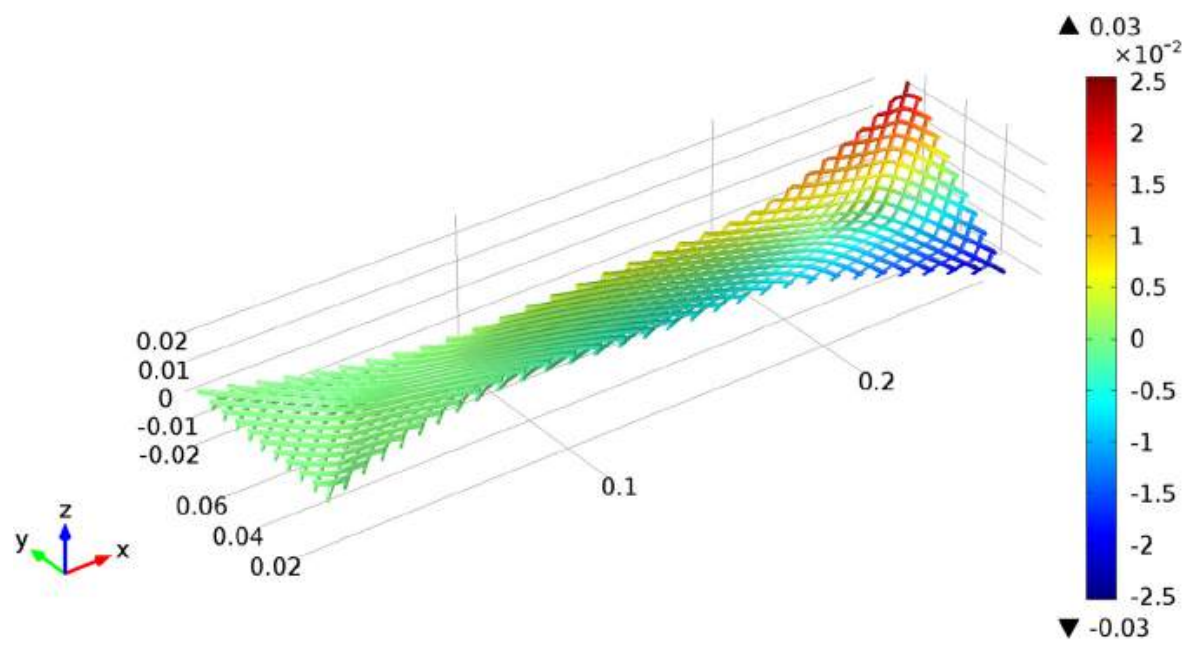

Fig. 23 Three-dimensional simulation for a pantographic structure in traction and torsion as studied in Ref. [359] (original picture by the authors) 


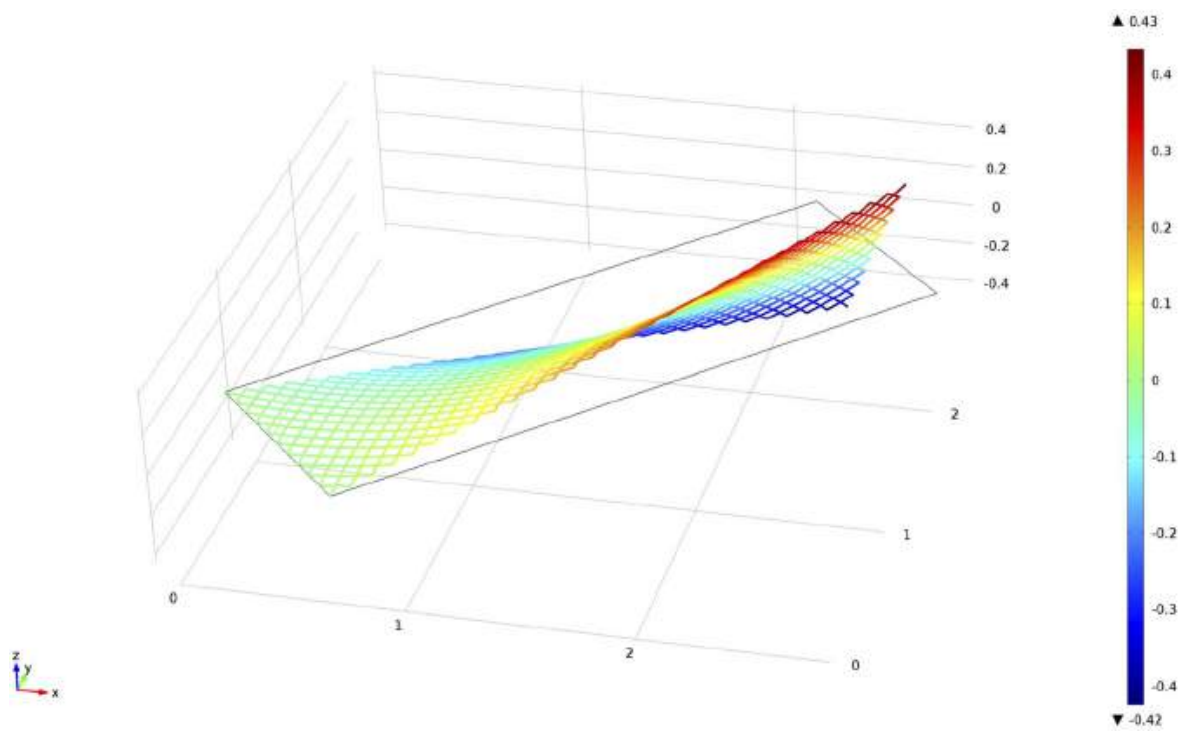

Fig. 24 Out-of-plane twisting of a pantographic sheet with combined traction and torsion as studied in Ref. [358]. The picture is relative to a continuum simulation, and that the curves represent sets of material points which are straight lines in the reference configuration (original picture by the authors).

coupled due to the interplay among strain, normal bending, twisting, and geodesic bending.

One very ambitious field of application in this field of research is the analysis of the response of recently developed bio-inspired flexible electronics for health-monitoring purposes, such as those developed by the group led by Nanshu Lu (see, for instance, Ref. [361]). In this research, a generalization of the aforementioned pantographic structure is proposed (see Fig. 20), which conforms mechanically to skin tissue (for details on this topic, see Refs. [362-368]), i.e., electronic systems that remain congruent to the epidermis as it deforms. These structures may exhibit complex large-deformation behavior, including out-of-plane buckling induced by in-plane extension. Their mechanical behavior is such that other soft-tissue biomimetic applications are possible (see Fig. 21 for the employment of a similarly conceived architectured material for a vascular prosthesis). Understanding the mechanics of these kinds of structures, as well as deepening our knowledge of mechanophysiology of the skin, will be crucial in order to exploit their potential (Figs. 22-24).

\section{Conclusions}

Modern technology is experiencing a tumultuous growth. This growth is producing wonderful and unexpected devices, mechanisms, tools, and some solutions to many among the problems humankind is facing since its appearance on Earth. All these developments are based on what can be considered the deepest and most detailed scientific understanding of Nature ever attained. The situation is very similar to what experienced during the Renaissance when, based on the rediscovery (see again Ref. [1]) of Hellenistic science, Italian (and in general Western) scientists started to shape the modern human society, which systematically exploits innovation, scientific knowledge, and technological transfer to increase its productive capability and, at the end, the quality of life of humankind.

It is therefore suitable even nowadays to address the methodological considerations and innovation thrusts which animated all Renaissance men, and, first among them, Galileo Galilei. In Galileo's Il Saggiatore (Ref. [370], p. 232), we can read: ${ }^{4}$

${ }^{4}$ The authors want to note that it is unfortunate that it is not easy to find a complete translation into English of all the works by Galileo.
La filosofia è scritta in questo grandissimo libro che continuamente ci sta aperto innanzi a gli occhi (io dico l'universo) ma non si può intendere se prima non s'impara a intender la lingua, e conoscer i caratteri, ne' quali è scritto. Egli è scritto in lingua matematica, e i caratteri son triangoli, cerchi ed altre figura geometriche, senza i quali mezzi è impossibile a intenderne umanamente parola; senza questi è un aggirarsi vanamente per un oscuro laberinto.

Which is translated by Stillman Drake (in Ref. [371]) as:

Philosophy is written in this grand book, the universe, which stands continually open to our gaze. But the book cannot be understood unless one first learns to comprehend the language and read the letters in which it is composed. It is written in the language of mathematics, and its characters are triangles, circles, and other geometric figures without which it is humanly impossible to understand a single word of it; without these, one wanders about in a dark labyrinth.

One should not believe that Galileo is accepting the philosophical vision which is currently known as "Platonistic." Galileo (and ourselves) did not believe that mathematics is a reality outside our mind: he claims indeed that "Philosophy" is written in the language of mathematics and that the universe can be understood only when using a philosophy which exploits the scientific logical-deductive method and the tools given to us by mathematics.

Engineering sciences must be based on a preliminary deep understanding of the nature of the phenomena which it intends to exploit for developing its applications. Therefore, mathematical formulation of predictive models is essential in Engineering. Moreover, the attentive observer will discover that, indeed, mathematics and mathematical knowledge have shaped and are shaping our environment, our world or, if you like, our "ecological niche" via the engineering applications and technology which they ultimately make possible. It is not the world which is written in mathematical symbols: it is our mind which shapes the world using mathematics as a fundamental tool for understanding, predicting, and controlling the phenomena, and for designing the artifacts which surround us. It is therefore natural that one recognizes in the artifacts the mathematics which is behind them. One instance will clarify the issue: even if Navier's effort to design a suspension bridge based on mathematical modeling failed because of lack of knowledge about the mechanical behavior of 
foundations (and this failure pushed the development of geotechnics), when Navier "Mathematizes" the study of suspension bridges he establishes the methods needed to cross large spans without intermediate pillars and therefore changes the shape of our cities, our highways, and our railways (see, for instance, Ref. [372] and [373]). Similarly, the concept of tube-frame structural system, based on the highly mathematically based theory of structures, was developed, among the others, by Fazlur Rahman Khan and was used to build the twin towers and many subsequent skyscrapers. Moreover, it is also to be pointed out that our failures in understanding mathematical problems play an important role as our successes in determining our technology. For example, it is well known that Warren bridge was mainly chosen, among many possible structures, because of the fact that having loads concentrated on the nodes (usually modeled by means of ideal hinges) heavily cuts the computational costs, making the problem solvable even in an age in which computers were not yet available; this is the reason for which, still today, this kind of structures is so often employed even if our software can easily deal with the computation needed by distributed bending loads in most of the cases.

In the present review, we wanted to stress that mathematics is starting to shape novel "exotic" fabric materials. Indeed their structure is determined "a priori" via the mathematical equations which one decides must be those governing their physical behavior. The limits in this design and conception process coincide with the limits of the mathematics which we are able to handle. Exactly as happened during Navier's age, when the lack of mathematical and mechanical knowledge limited the capability of building bridges, nowadays the limits of the mathematical and mechanical theories and models risk to impose restrictions on the technological capabilities of humankind, and in particular on the materials which are available for our engineering applications. To be able to improve the performances of materials, to increase their capacity to sustain thermal, mechanical, or electrical external actions, one needs to develop new and more powerful mathematical, mechanical, and numerical methods. In this sense, mathematics is one of the most practical tools which are available to the engineer. Moreover, the field of novel engineered materials systems requires new and powerful experimental techniques in order to validate and to inform any of the developed theories and models.

The authors hope that this review will contribute to the achievement of an effective overview of what has been done and what remains to be done in a part of the vast field of complex mechanical metamaterials design and prototyping.

\section{Acknowledgment}

The authors would like to thank Professor Claude Boutin, Professor Victor Eremeyev, Professsor Angelo Luongo, and Professor Pierre Seppecher for the precious help provided while working on the manuscript as well as in long years of fruitful scientific discussions.

\section{References}

[1] Russo, L., 2004, "The Forgotten Revolution. How Science Was Born in 300 BC and Why it Had to be Reinvented," Übersetzung aus dem Italienischen von Silvio Levy, Springer, Berlin.

[2] Germain, P., 1973, "The Method of Virtual Power in Continuum Mechanics. Part 2: Microstructure," SIAM J. Appl. Math., 25(3), pp. 556-575.

[3] Maugin, G., and Trimarco, C., 1992, "Pseudomomentum and Material Forces in Nonlinear Elasticity: Variational Formulations and Application to Brittle Fracture," Acta Mech., 94(1-2), pp. 1-28.

[4] Maugin, G. A., and Trimarco, C., 1992, "Note on a Mixed Variational Principle in Finite Elasticity," Atti Accad. Naz. Lincei, Cl. Sci. Fis., Mat. Nat., Rend. Lincei, Mat. Appl., 3(1), pp. 69-74.

[5] Arnold, V. I., 1989, Mathematical Methods of Classical Mechanics, Vol. 60, Springer Science \& Business Media, New York.

[6] Maugin, G., 1980, "The Method of Virtual Power in Continuum Mechanics: Application to Coupled Fields," Acta Mech., 35(1-2), pp. 1-70.

[7] Toupin, R. A., 1965, "Saint-Venant's Principle," Arch. Ration. Mech. Anal., 18(2), pp. 83-96.

[8] Mühlhaus, H.-B., and Alfantis, E., 1991, “A Variational Principle for Gradient Plasticity,” Int. J. Solids Struct., 28(7), pp. 845-857.
[9] Edelen, D. G., 1969, "Non-Local Variational Mechanics Variational Imbedding, Adjoint Theorems and Existence," Int. J. Eng. Sci., 7(4), pp. 401-415.

[10] dell'Isola, F., and Placidi, L., 2012, "Variational Principles are a Powerful Tool Also for Formulating Field Theories," Variational Models and Methods in Solid and Fluid Mechanics, Springer Science \& Business Media, Vienna, Austria.

[11] Kirchner, N., and Steinmann, P., 2005, "A Unifying Treatise on Variational Principles for Gradient and Micromorphic Continua," Philos. Mag., 85(33-35), pp. 3875-3895.

[12] Placidi, L., "A Variational Approach for a Nonlinear One-Dimensional Damage-Elasto-Plastic Second-Gradient Continuum Model," Continuum Mech. Thermodyn., epub.

[13] Placidi, L., "A Variational Approach for a Nonlinear 1-Dimensional Second Gradient Continuum Damage Model," Continuum Mech. Thermodyn., 27(4-5), pp. 623-638.

[14] Rahouadj, R., Ganghoffer, J.-F., and Cunat, C., 2003, "A Thermodynamic Approach With Internal Variables Using Lagrange Formalism. Part I: General Framework," Mech. Res. Commun., 30(2), pp. 109-117.

[15] Eremeyev, V. A., and Pietraszkiewicz, W., 2004, "The Nonlinear Theory of Elastic Shells With Phase Transitions," J. Elasticity, 74(1), pp. 67-86.

[16] Rahouadj, R., Ganghoffer, J.-F., and Cunat, C., 2003, "A Thermodynamic Approach With Internal Variables Using Lagrange Formalism. Part II. Continuous Symmetries in the Case of the Time-Temperature Equivalence," Mech. Res. Commun., 30(2), pp. 119-123.

[17] Ganghoffer, J., 2012, "Extremum Principles for Biological Continuous Bodies Undergoing Volumetric and Surface Growth,” Bull. Pol. Acad. Sci., 60(2), pp. 259-263.

[18] Serrano, H., 2014, "A Variational Approach to the Homogenization of Laminate Metamaterials," Nonlinear Anal., 18, pp. 75-85.

[19] Deü, J. F., Larbi, W., and Ohayon, R., 2008, "Piezoelectric Structural Acoustic Problems: Symmetric Variational Formulations and Finite Element Results," Comp. Meth. Appl. Mech. Eng., 197(19), pp. 1715-1724.

[20] Altenbach, H., Eremeyev, V. A., and Lebedev, L. P., 2010, "On the Existence of Solution in the Linear Elasticity With Surface Stresses,” J. Appl. Math. Mech./Z. Angew. Math. Mech., 90(3), pp. 231-240.

[21] Altenbach, H., Eremeyev, V. A., and Lebedev, L. P., 2011, "On the Spectrum and Stiffness of an Elastic Body With Surface Stresses," J. Appl. Math. Mech./Z. Angew. Math. Mech., 91(9), pp. 699-710.

[22] Eremeyev, V. A., and Lebedev, L. P., 2015, "Mathematical Study of Boundary-Value Problems Within the Framework of Steigmann-Ogden Model of Surface Elasticity," Continuum Mech. Thermodyn., epub.

[23] Eremeyev, V. A., and Lebedev, L. P., 2011, "Existence Theorems in the Linear Theory of Micropolar Shells," J. Appl. Math. Mech./Z. Angew. Math. Mech., 91(6), pp. 468-476.

[24] Eremeyev, V. A., and Lebedev, L. P., 2013, "Existence of Weak Solutions in Elasticity," Math. Mech. Solids, 18(2), pp. 204-217.

[25] Ortiz, M., and Stainier, L., 1999, "The Variational Formulation of Viscoplastic Constitutive Updates," Comput. Methods Appl. Mech. Eng., 171(3), pp. 419-444.

[26] Liu, C., Li, F., Ma, L.-P., and Cheng, H.-M., 2010, "Advanced Materials for Energy Storage," Adv. Mater., 22(8), pp. E28-E62.

[27] Caruso, F., 2001, "Nanoengineering of Particle Surfaces," Adv. Mater., 13(1), pp. 11-22.

[28] Coleman, J. N., Khan, U., and Gun'ko, Y. K., 2006, "Mechanical Reinforcement of Polymers Using Carbon Nanotubes," Adv. Mater., 18(6), pp. 689-706.

[29] Hammond, P. T., 2004, "Form and Function in Multilayer Assembly: New Applications at the Nanoscale," Adv. Mater., 16(15), pp. 1271-1293.

[30] Fleck, N., Deshpande, V., and Ashby, M., 2010, "Micro-Architectured Materials: Past, Present and Future," Proc. R. Soc. London A, 466(2121), pp. 2495-2516.

[31] Dunlop, J. W., and Fratzl, P., 2013, "Multilevel Architectures in Natural Materials," Scr. Mater., 68(1), pp. 8-12.

[32] Brechet, Y., and Embury, J., 2013, "Architectured Materials: Expanding Materials Space," Scr. Mater., 68(1), pp. 1-3.

[33] Bouaziz, O., Brechet, Y., and Embury, J., 2008, "Heterogeneous and Architectured Materials: A Possible Strategy for Design of Structural Materials," Adv. Eng. Mater., 10(1-2), pp. 24-36.

[34] Bollen, P., Quiévy, N., Huynen, I., Bailly, C., Detrembleur, C., Thomassin, J.-M., and Pardoen, T., 2013, "Multifunctional Architectured Materials for Electromagnetic Absorption," Scr. Mater., 68(1), pp. 50-54.

[35] Ashby, M., 2013, "Designing Architectured Materials," Scr. Mater., 68(1), pp. 4-7.

[36] Ashby, M., and Brechet, Y., 2003, "Designing Hybrid Materials," Acta Mater., 51(19), pp. 5801-5821.

[37] Griesshaber, E., Schmahl, W. W., Neuser, R., Pettke, T., Blüm, M., Mutterlose, J., and Brand, U., 2007, "Crystallographic Texture and Microstructure of Terebratulide Brachiopod Shell Calcite: An Optimized Materials Design With Hierarchical Architecture," Am. Mineral., 92(5-6), pp. 722-734.

[38] Bruchhaus, R., Honal, M., Symanczyk, R., and Kund, M., 2009, "Selection of Optimized Materials for CBRAM Based on HT-XRD and Electrical Test Results," J. Electrochem. Soc., 156(9), pp. H729-H733.

[39] Vetterl, O., Finger, F., Carius, R., Hapke, P., Houben, L., Kluth, O., Lambertz, A., Mück, A., Rech, B., and Wagner, H., 2000, "Intrinsic Microcrystalline Silicon: A New Material for Photovoltaics," Sol. Energy Mater. Sol. Cells, 62(1), pp. 97-108.

[40] Zheludev, N. I., 2010, "The Road Ahead for Metamaterials," Science, 328(5978), pp. 582-583.

[41] Ju, J., Summers, J. D., Ziegert, J., and Fadel, G., 2009, "Design of Honeycomb Meta-Materials for High Shear Flexure," ASME Paper No. DETC2009-87730. 
[42] Engheta, N., and Ziolkowski, R. W., 2006, Metamaterials: Physics and Engineering Explorations, Wiley, Hoboken, NJ.

[43] Del Vescovo, D., and Giorgio, I., 2014, "Dynamic Problems for Metamaterials: Review of Existing Models and Ideas for Further Research,” Int. J. Eng. Sci., 80(SI), pp. 153-172.

[44] Milton, G., and Seppecher, P., 2012, "A Metamaterial Having a Frequency Dependent Elasticity Tensor and a Zero Effective Mass Density," Phys. Status Solidi (B), 249(7), pp. 1412-1414.

[45] Kang, I., Heung, Y. Y., Kim, J. H., Lee, J. W., Gollapudi, R., Subramaniam, S., Narasimhadevara, S., Hurd, D., Kirikera, G. R., Shanov, V., Schulz, M. J., Shi, D., Boerio, J., Mall, S., and Ruggles-Wren, M., 2006, "Introduction to Carbon Nanotube and Nanofiber Smart Materials," Composites, Part B, 37(6), pp. 382-394.

[46] Wang, Z. L., 1998, Functional and Smart Materials, Wiley Online Library, Hoboken, NJ.

[47] Giurgiutiu, V., 2000, "Review of Smart-Materials Actuation Solutions for Aeroelastic and Vibration Control,” J. Intell. Mater. Syst. Struct., 11(7), pp. 525-544.

[48] Song, Y., Wei, W., and Qu, X., 2011, "Colorimetric Biosensing Using Smart Materials," Adv. Mater., 23(37), pp. 4215-4236.

[49] Chopra, I., 2002, "Review of State of Art of Smart Structures and Integrated Systems," AIAA J., 40(11), pp. 2145-2187.

[50] Vernerey, F., Liu, W. K., and Moran, B., 2007, "Multi-Scale Micromorphic Theory for Hierarchical Materials," J. Mech. Phys. Solids, 55(12), pp. 2603-2651.

[51] Nicot, F., Darve, F., and Group, R., 2005, "A Multi-Scale Approach to Granular Materials," Mech. Mater., 37(9), pp. 980-1006.

[52] Bentz, D., 2000, "Influence of Silica Fume on Diffusivity in Cement-Based Materials: II. Multi-Scale Modeling of Concrete Diffusivity," Cem. Concr. Res., 30(7), pp. 1121-1129.

[53] Fast, T., Niezgoda, S. R., and Kalidindi, S. R., 2011, “A New Framework for Computationally Efficient Structure-Structure Evolution Linkages to Facilitate High-Fidelity Scale Bridging in Multi-Scale Materials Models," Acta Mater., 59(2), pp. 699-707.

[54] Hao, S., Moran, B., Liu, W. K., and Olson, G. B., 2003, "A Hierarchical Multi-Physics Model for Design of High Toughness Steels," J. Comput. Aided Mater. Des., 10(2), pp. 99-142.

[55] de Borst, R., 2008, "Challenges in Computational Materials Science: Multiple Scales, Multi-Physics and Evolving Discontinuities," Comput. Mater. Sci., 43(1), pp. 1-15.

[56] Hamilton, R., MacKenzie, D., and Li, H., 2010, "Multi-Physics Simulation of Friction Stir Welding Process," Eng. Comput., 27(8), pp. 967-985.

[57] Eremeyev, V., and Pietraszkiewicz, W., 2009, "Phase Transitions in Thermoelastic and Thermoviscoelastic Shells," Arch. Mech., 61(1), pp. 41-67.

[58] Eremeyev, V., and Pietraszkiewicz, W., 2011, "Thermomechanics of Shells Undergoing Phase Transition,” J. Mech. Phys. Solids, 59(7), pp. 1395-1412.

[59] Pietraszkiewicz, W., Eremeyev, V., and Konopińska, V., 2007, "Extended Non-Linear Relations of Elastic Shells Undergoing Phase Transitions," Z. Angew. Math. Mech., 87(2), pp. 150-159.

[60] Piccardo, G., and Solari, G., 2000, "3D Wind-Excited Response of Slender Structures: Closed-Form Solution,” J. Struct. Eng., 126(8), pp. 936-943.

[61] Piccardo, G., 1993, "A Methodology for the Study of Coupled Aeroelastic Phenomena," J. Wind Eng. Ind. Aerodyn., 48(2), pp. 241-252.

[62] de Villoria, R. G., Yamamoto, N., Miravete, A., and Wardle, B. L., 2011, "Multi-Physics Damage Sensing in Nano-Engineered Structural Composites," Nanotechnology, 22(18), p. 185502

[63] Alessandroni, S., Andreaus, U., dell'Isola, F., and Porfiri, M., 2004, "PiezoElectromechanical (PEM) Kirchhoff-Love Plates," Eur. J. Mech. A, 23(4), pp. 689-702.

[64] Placidi, L., and Hutter, K., 2006, "Thermodynamics of Polycrystalline Materials Treated by the Theory of Mixtures With Continuous Diversity," Continuum Mech. Thermodyn., 17(6), pp. 409-451.

[65] Andreaus, U., and Porfiri, M., 2007, "Effect of Electrical Uncertainties on Resonant Piezoelectric Shunting," J. Intell. Mater. Syst. Struct., 18(5), pp. $477-485$

[66] Kim, D.-H., Song, J., Choi, W. M., Kim, H.-S., Kim, R.-H., Liu, Z., Huang, Y. Y., Hwang, K.-C., Zhang, Y.-w., and Rogers, J. A., 2008, "Materials and Noncoplanar Mesh Designs for Integrated Circuits With Linear Elastic Responses to Extreme Mechanical Deformations," Proc. Natl. Acad. Sci., 105(48), pp. 18675-18680.

[67] Mannsfeld, S. C., Tee, B. C., Stoltenberg, R. M., Chen, C. V. H., Barman, S., Muir, B. V., Sokolov, A. N., Reese, C., and Bao, Z., 2010, "Highly Sensitive Flexible Pressure Sensors With Microstructured Rubber Dielectric Layers," Nat. Mater., 9(10), pp. 859-864.

[68] Maurini, C., Pouget, J., and dell'Isola, F., 2004, "On a Model of Layered Piezoelectric Beams Including Transverse Stress Effect," Int. J. Solids Struct., 41(16), pp. 4473-4502.

[69] Lakes, R., 1993, "Advances in Negative Poisson's Ratio Materials," Adv. Mater., 5(4), pp. 293-296.

[70] Lakes, R., and Drugan, W., 2002, "Dramatically Stiffer Elastic Composite Materials Due to a Negative Stiffness Phase?" J. Mech. Phys. Solids, 50(5), pp. 979-1009.

[71] Jaglinski, T., Kochmann, D., Stone, D., and Lakes, R., 2007, "Composite Materials With Viscoelastic Stiffness Greater Than Diamond," Science, 315(5812), pp. 620-622.

[72] Bertoldi, K., Reis, P. M., Willshaw, S., and Mullin, T., 2010, "Negative Poisson's Ratio Behavior Induced by an Elastic Instability," Adv. Mat., 22(3), pp. 361-366.
[73] Kashdan, L., Conner Seepersad, C., Haberman, M., and Wilson, P. S., 2012, "Design, Fabrication, and Evaluation of Negative Stiffness Elements Using SLS," Rapid Prototyping J., 18(3), pp. 194-200.

[74] Milton, G. W., 2002, "The Theory of Composites," Cambridge Monographs on Applied and Computational Mathematics, Cambridge University Press, Cambridge, UK.

[75] Nikopour, H., and Selvadurai, A., 2013, "Torsion of a Layered Composite Strip,” Compos. Struct., 95, pp. 1-4.

[76] Nikopour, H., and Selvadurai, A., 2014, "Concentrated Loading of a FibreReinforced Composite Plate: Experimental and Computational Modeling of Boundary Fixity," Composites, Part B, 60, pp. 297-305.

[77] Placidi, L., and Hutter, K., 2005, "An Anisotropic Flow Law for Incompressible Polycrystalline Materials,” Z. Angew. Math. Phys., 57(1), pp. 160-181.

[78] Selvadurai, A., and Nikopour, H., 2012, "Transverse Elasticity of a Unidirectionally Reinforced Composite With an Irregular Fibre Arrangement: Experiments, Theory and Computations," Compos. Struct., 94(6), pp. 1973-1981.

[79] Arnold, C. B., Serra, P., and Piqué, A., 2007, "Laser Direct-Write Techniques for Printing of Complex Materials," MRS Bull., 32(1), pp. 23-31.

[80] Pershin, Y. V., and Di Ventra, M., 2011, "Memory Effects in Complex Materials and Nanoscale Systems," Adv. Phys., 60(2), pp. 145-227.

[81] Proffen, T., Billinge, S., Egami, T., and Louca, D., 2003, "Structural Analysis of Complex Materials Using the Atomic Pair Distribution Function-A Practical Guide,” Z. Kristallogr./Int. J. Struct. Phys. Chem. Aspects Cryst. Mater., 218(2), pp. 132-143.

[82] Grillo, A., Federico, S., and Wittum, G., 2012, "Growth, Mass Transfer, and Remodeling in Fiber-Reinforced, Multi-Constituent Materials," Int. J. Nonlinear Mech., 47(2), pp. 388-401.

[83] Grillo, A., Federico, S., Wittum, G., Imatani, S., Giaquinta, G., and Mićunović, M. V., 2009, "Evolution of a Fibre-Reinforced Growing Mixture," Nuovo Cimento C, 32C(1), pp. 97-119.

[84] Grillo, A., and Wittum, G., 2010, "Growth and Mass Transfer in MultiConstituent Biological Materials,” AIP Conf. Proc., 1281(1), pp. 355-358.

[85] Seddik, H., Greve, R., Zwinger, T., and Placidi, L., 2011, "A Full Stokes Ice Flow Model for the Vicinity of Dome Fuji, Antarctica, With Induced Anisotropy and Fabric Evolution," Cryosphere, 5(2), pp. 495-508.

[86] Porubov, A. V., Aero, E. L., and Andrievsky, B., 2010, "Dynamic Properties of Essentially Nonlinear Generalized Continua," Mechanics of Generalized Continua, Springer, New York, pp. 161-168.

[87] Forest, S., 1998, "Mechanics of Generalized Continua: Construction by Homogenization," J. Phys. IV, 8(PR4), pp. PR4-PR39.

[88] Maugin, G. A., and Metrikine, A. V., 2010, "Mechanics of Generalized Continua," Advances in Mechanics and Mathematics, Vol. 21, Springer, New York.

[89] Tekoğlu, C., and Onck, P. R., 2008, "Size Effects in Two-Dimensional Voronoi Foams: A Comparison Between Generalized Continua and Discrete Models," J. Mech. Phys. Solids, 56(12), pp. 3541-3564.

[90] Forest, S., and Trinh, D. K., 2011, "Generalized Continua and NonHomogeneous Boundary Conditions in Homogenisation Methods," ZAMM, 91(2), pp. 90-109.

[91] Boutin, C., Hans, S., and Chesnais, C., 2010, "Generalized Beams and Continua. Dynamics of Reticulated Structures," Mechanics of Generalized Continua, Springer, New York, pp. 131-141.

[92] Feyel, F., 2003, "A Multilevel Finite Element Method (FE 2) to Describe the Response of Highly Non-Linear Structures Using Generalized Continua," Comput. Methods Appl. Mech. Eng., 192(28), pp. 3233-3244.

[93] Forest, S., and Sievert, R., 2003, "Elastoviscoplastic Constitutive Frameworks for Generalized Continua," Acta Mechanica 160(1-2), pp. 71-111.

[94] Green, A., and Naghdi, P., 1995, "A Unified Procedure for Construction of Theories of Deformable Media. II. Generalized Continua," Proc. R. Soc. London A, 448(1934), pp. 357-377.

[95] Eringen, A. C., 1965, "Theory of Micropolar Fluids," DTIC Document, Technical Report No. 27.

[96] Eringen, A. C., and Suhubi, E., 1964, "Nonlinear Theory of Simple MicroElastic Solidsi," Int. J. Eng. Sci., 2(2), pp. 189-203.

[97] Eringen, A. C., 1999, "Theory of Micropolar Elasticity," Microcontinuum Field Theories, Springer, New York, pp. 101-248.

[98] Mindlin, R. D., 1964, "Micro-Structure in Linear Elasticity," Arch. Ration. Mech. Anal., 16(1), pp. 51-78.

[99] Eringen, A. C., 2012, Microcontinuum Field Theories: I. Foundations and Solids. Springer Science \& Business Media, New York.

[100] Neff, P., Ghiba, I.-D., Madeo, A., Placidi, L., and Rosi, G., 2013, “A Unifying Perspective: The Relaxed Linear Micromorphic Continuum," Continuum Mech. Thermodyn., 26(5), pp. 639-681.

[101] Neff, P., 2004, "On Material Constants for Micromorphic Continua," Trends in Applications of Mathematics to Mechanics, XIVth International Symposium on Trends in Applications of Mathematics to Mechanics (STAMM'2004), Seeheim, Germany, Aug. 22-28, pp. 337-348.

[102] Misra, A., and Singh, V., 2013, "Micromechanical Model for ViscoelasticMaterials Undergoing Damage," Continuum Mech. Thermodyn., 25(2), pp. 1-16.

[103] Misra, A., and Yang, Y., 2010, "Micromechanical Model for Cohesive Materials Based Upon Pseudo-Granular Structure," Int. J. Solids Struct., 47(21), pp. 2970-2981.

[104] Contrafatto, L., Cuomo, M., and Fazio, F., 2012, “An Enriched Finite Element for Crack Opening and Rebar Slip in Reinforced Concrete Members," Int. J. Fract., 178(1-2), pp. 33-50.

[105] Scerrato, D., Giorgio, I., Della Corte, A., Madeo, A., and Limam, A., 2015, "A Micro-Structural Model for Dissipation Phenomena in the Concrete," Int. J. Numer. Anal. Methods Geomech., 39(18), pp. 2037-2052. 
[106] Scerrato, D., Giorgio, I., Madeo, A., Limam, A., and Darve, F., 2014, "A Simple Non-Linear Model for Internal Friction in Modified Concrete," Int. J. Eng. Sci., 80(SI), pp. 136-152.

[107] Boutin, C., 1996, "Microstructural Effects in Elastic Composites," Int. J. Solids Struct., 33(7), pp. 1023-1051.

[108] Eringen, A. C., 1968, Mechanics of Micromorphic Continua, Springer, Berlin.

[109] Bréchet, Y., 2000, Microstructures, Mechanical Properties and Processes, Wiley-VCH, Weinheim, Germany.

[110] Leismann, T., and Mahnken, R., 2015, "Comparison of Micromorphic, Micropolar and Microstrain Continua," Book of Abstracts-Extract, 86th Annual Meeting of the International Association of Applied Mathematics and Mechanics (GAMM 2015), Lecce, Italy, Mar. 23-27, Università del Salento, Lecce, Italy, p. 58.

[111] Kim, D., Brunski, J., and Nicolella, D., 2005, "Microstrain Fields for Cortical Bone in Uniaxial Tension: Optical Analysis Method," Proc. Inst. Mech. Eng., Part H, 219(2), pp. 119-128.

[112] Yang, Y., and Misra, A., 2012, "Micromechanics Based Second Gradient Continuum Theory for Shear Band Modeling in Cohesive Granular Materials Following Damage Elasticity," Int. J. Solids Struct., 49(18), pp. 2500-2514.

[113] Yang, Y., Ching, W., and Misra, A., 2011, "Higher-Order Continuum Theory Applied to Fracture Simulation of Nanoscale Intergranular Glassy Film," J. Nanomech. Micromech., 1(2), pp. 60-71.

[114] Seppecher, P., 2002, "Second-Gradient Theory: Application to Cahn-Hilliard Fluids," Continuum Thermomechanics, Springer, New York, pp. 379-388.

[115] Alibert, J.-J., Seppecher, P., and dell'Isola, F., 2003, “Truss Modular Beams With Deformation Energy Depending on Higher Displacement Gradients," Math. Mech. Solids, 8(1), pp. 51-73.

[116] Neff, P., Chełmiński, K., and Alber, H.-D., 2009, "Notes on Strain Gradient Plasticity: Finite Strain Covariant Modelling and Global Existence in the Infinitesimal Rate-Independent Case," Math. Models Methods Appl. Sci., 19(2), pp. 307-346.

[117] Placidi, L., Rosi, G., Giorgio, I., and Madeo, A., 2014, "Reflection and Transmission of Plane Waves at Surfaces Carrying Material Properties and Embedded in Second-Gradient Materials," Math. Mech. Solids, 19(5), pp. 555-578.

[118] Askes, H., Suiker, A., and Sluys, L., 2002, "A Classification of Higher-Order Strain-Gradient Models-Linear Analysis," Arch. Appl. Mech., 72(2-3), pp. $171-188$

[119] Rinaldi, A., and Placidi, L., 2013, "A Microscale Second Gradient Approximation of the Damage Parameter of Quasi-Brittle Heterogeneous Lattices," Z. Angew. Math. Mech./J. Appl. Math. Mech., 94(10), pp. 862-877.

[120] Iordache, M.-M., and Willam, K., 1998, "Localized Failure Analysis in Elastoplastic Cosserat Continua," Comput. Methods Appl. Mech. Eng., 151(3), pp. 559-586.

[121] Perić, D., Yu, J., and Owen, D., 1994, “On Error Estimates and Adaptivity in Elastoplastic Solids: Applications to the Numerical Simulation of Strain Localization in Classical and Cosserat Continua," Int. J. Numer. Methods Eng., 37(8), pp. 1351-1379.

[122] Ehlers, W., Ramm, E., Diebels, S., and dAddetta, G., 2003, "From Particle Ensembles to Cosserat Continua: Homogenization of Contact Forces Towards Stresses and Couple Stresses," Int. J. Solids Struct., 40(24), pp. 6681-6702.

[123] Neuber, H., 1966, "On the General Solution of Linear-Elastic Problems in Isotropic and Anisotropic Cosserat Continua," Applied Mechanics, Springer, Berlin, pp. 153-158.

[124] Dietsche, A., and Willam, K., 1997, "Boundary Effects in Elasto-Plastic Cosserat Continua,” Int. J. Solids Struct., 34(7), pp. 877-893.

[125] Ieşan, D., 2007, "A Theory of Thermoviscoelastic Composites Modelled as Interacting Cosserat Continua," J. Therm. Stresses, 30(12), pp. 1269-1289.

[126] Pietraszkiewicz, W., and Eremeyev, V., 2009, "On Vectorially Parameterized Natural Strain Measures of the Non-Linear Cosserat Continuum," Int. J. Solids Struct., 46(11), pp. 2477-2480.

[127] Altenbach, J., Altenbach, H., and Eremeyev, V. A., 2010, "On Generalized Cosserat-Type Theories of Plates and Shells: A Short Review and Bibliography," Arch. Appl. Mech., 80(1), pp. 73-92.

[128] Steinmann, P., and Stein, E., 1997, "A Unifying Treatise of Variational Principles for Two Types of Micropolar Continua," Acta Mech., 121(1-4), pp. 215-232.

[129] Eremeyev, V. A., and Pietraszkiewicz, W., "Material Symmetry Group and Constitutive Equations of Micropolar Anisotropic Elastic Solids," Math. Mech. Solids, epub.

[130] Eremeyev, V. A., and Pietraszkiewicz, W., 2012, "Material Symmetry Group of the Non-Linear Polar-Elastic Continuum," Int. J. Solids Struct., 49(14), pp. 1993-2005.

[131] Pietraszkiewicz, W., and Eremeyev, V., 2009, "On Natural Strain Measures of the Non-Linear Micropolar Continuum," Int. J. Solids Struct., 46(3), pp. 774-787.

[132] Jänicke, R., Diebels, S., Sehlhorst, H.-G., and Düster, A., 2009, "Two-Scale Modelling of Micromorphic Continua," Continuum Mech. Thermodyn., 21(4), pp. 297-315

[133] Forest, S., and Sievert, R., 2006, "Nonlinear Microstrain Theories,” Int. J. Solids Struct., 43(24), pp. 7224-7245.

[134] dell'Isola, F., Andreaus, U., and Placidi, L., 2014, "At the Origins and in the Vanguard of Peridynamics, Non-Local and Higher-Gradient Continuum Mechanics: An Underestimated and Still Topical Contribution of Gabrio Piola," Math. Mech. Solids, 20(8), pp. 887-928.

[135] Carcaterra, A., dell'Isola, F., Esposito, R., and Pulvirenti, M., 2015, "Macroscopic Description of Microscopically Strongly Inhomogeneous Systems: A Mathematical Basis for the Synthesis of Higher Gradients Metamaterials," Arch. Ration. Mech. Anal., 218(3), pp. 1239-1262.
[136] Alibert, J. J., and Corte, A. D., 2015, "Second-Gradient Continua as Homogenized Limit of Pantographic Microstructured Plates: A Rigorous Proof,' Z. Angew. Math. Phys., 66(5), pp. 2855-2870.

[137] Giorgio, I., Galantucci, L., Della Corte, A., and Del Vescovo, D., 2015, "Piezo-Electromechanical Smart Materials With Distributed Arrays of Piezoelectric Transducers: Current and Upcoming Applications," Int. J. Appl. Electromagn. Mech., 47(4), pp. 1051-1084.

[138] Trinh, D. K., Janicke, R., Auffray, N., Diebels, S., and Forest, S., 2012 "Evaluation of Generalized Continuum Substitution Models for Heterogeneous Materials," Int. J. Multiscale Comput. Eng., 10(6), pp. 527-549.

[139] Ashby, M. F., and Cebon, D., 1993, "Materials Selection in Mechanical Design," J. Phys. IV, 3(C7), pp. C7-1-C7-9.

[140] Elanchezhian, C., and Sundar, G. S., 2007, Computer Aided Manufacturing, Firewall Media, New Delhi, India.

[141] Auffray, N., dellIsola, F., Eremeyev, V., Madeo, A., and Rosi, G., 2015 "Analytical Continuum Mechanics à la Hamilton-Piola Least Action Principle for Second Gradient Continua and Capillary Fluids," Math. Mech. Solids, 20(4), pp. 375-417.

[142] Milton, G. W., and Willis, J. R., 2007, “On Modifications of Newton's Second Law and Linear Continuum Elastodynamics," Proc. R. Soc. London A, 463(2079), pp. 855-880.

[143] Metropolis, N., 1987, "The Beginning of the Monte Carlo Method," Los Alamos Sci., Special Issue, pp. 125-130.

[144] Happ, H. H., and Kron, G., 1973, Gabriel Kron and Systems Theory, Union College Press, Schenectady, NY.

[145] Zienkiewicz, O. C., Taylor, R. L., Zienkiewicz, O. C., and Taylor, R. L., 1977, The Finite Element Method, Vol. 3, McGraw-Hill, London, UK.

[146] Greco, L., Impollonia, N., and Cuomo, M., 2014, "A Procedure for the Static Analysis of Cable Structures Following Elastic Catenary Theory,” Int. J. Solids Struct., 51(7), pp. 1521-1533.

[147] Greco, L., and Cuomo, M., 2012, "On the Force Density Method for Slack Cable Nets," Int. J. Solids Struct., 49(13), pp. 1526-1540.

[148] Garusi, E., Tralli, A., and Cazzani, A., 2004, “An Unsymmetric Stress Formulation for Reissner-Mindlin Plates: A Simple and Locking-Free Rectangular Element," Int. J. Comput. Eng. Sci., 5(3), pp. 589-618.

[149] Reccia, E., Cazzani, A., and Cecchi, A., 2012, "FEM-DEM Modeling for Outof-Plane Loaded Masonry Panels: A Limit Analysis Approach," Open Civil Eng. J., 6(1), pp. 231-238.

[150] Greco, L., and Cuomo, M., 2014, "Consistent Tangent Operator for an Exact Kirchhoff Rod Model," Continuum Mech. Thermodyn., 27(4-5), pp. 861-877.

[151] Carassale, L., and Piccardo, G., 2010, "Non-Linear Discrete Models for the Stochastic Analysis of Cables in Turbulent Wind," Int. J. Nonlinear Mech., 45(3), pp. 219-231.

[152] Javili, A., and Steinmann, P., 2009, "A Finite Element Framework for Continua With Boundary Energies. Part I: The Two-Dimensional Case," Comput. Meth. Appl. Mech. Eng., 198(27), pp. 2198-2208.

[153] Javili, A., and Steinmann, P., 2010, "A Finite Element Framework for Continua With Boundary Energies. Part II: The Three-Dimensional Case," Comput. Methods Appl. Mech. Eng., 199(9), pp. 755-765.

[154] Turco, E., and Caracciolo, P., 2000, "Elasto-Plastic Analysis of Kirchhoff Plates by High Simplicity Finite Elements," Comput. Methods Appl. Mech. Eng., 190(5-7), pp. 691-706.

[155] Ciancio, D., Carol, I., and Cuomo, M., 2007, "Crack Opening Conditions at 'Corner Nodes' in FE Analysis With Cracking Along Mesh Lines," Eng. Fracture Mech., 74(13), pp. 1963-1982.

[156] Ciancio, D., Carol, I., and Cuomo, M., 2006, "On Inter-Element Forces in the FEM-Displacement Formulation, and Implications for Stress Recovery," Int J. Numer. Methods Eng., 66(3), pp. 502-528.

[157] Hughes, T. J., Cottrell, J. A., and Bazilevs, Y., 2005, "Isogeometric Analysis: CAD, Finite Elements, NURBS, Exact Geometry and Mesh Refinement," Comput. Methods Appl. Mech. Eng., 194(39), pp. 4135-4195.

[158] Cazzani, A., Malagù, M., and Turco, E., "Isogeometric Analysis of PlaneCurved Beams," Math. Mech. Solids, epub.

[159] Greco, L., and Cuomo, M., 2013, "B-Spline Interpolation of Kirchhoff-Love Space Rods," Comput. Methods Appl. Mech. Eng., 256, pp. 251-269.

[160] Greco, L., and Cuomo, M., 2014, "An Implicit G1 Multi Patch B-Spline Interpolation for Kirchhoff-Love Space Rod," Comput. Methods Appl. Mech. Eng., 269, pp. 173-197.

[161] Cazzani, A., Malagù, M., and Turco, E., 2014, "Isogeometric Analysis: A Powerful Numerical Tool for the Elastic Analysis of Historical Masonry Arches," Continuum Mech. Thermodyn., epub.

[162] Cazzani, A., Malagù, M., Turco, E., and Stochino, F., "Constitutive Model for Strongly Curved Beams in the Frame of Isogeometric Analysis," Math. Mech. Solids, epub.

[163] Cuomo, M., Contrafatto, L., and Greco, L., 2014, "A Variational Model Based on Isogeometric Interpolation for the Analysis of Cracked Bodies," Int. J. Eng. Sci., 80(SI), pp. 173-188.

[164] De Luycker, E., Benson, D., Belytschko, T., Bazilevs, Y., and Hsu, M., 2011, "X-FEM in Isogeometric Analysis for Linear Fracture Mechanics," Int. J. Numer. Methods Eng., 87(6), pp. 541-565.

[165] Allen, M. P., 2004, "Introduction to Molecular Dynamics Simulation," Comput. Soft Matter, 23, pp. 1-28.

[166] Tinsley Oden, J., Prudhomme, S., Romkes, A., and Bauman, P. T., 2006, "Multiscale Modeling of Physical Phenomena: Adaptive Control of Models," SIAM J. Sci. Comput., 28(6), pp. 2359-2389.

[167] Piola, G., 2014, The Complete Works of Gabrio Piola: Commented English Translation, Vol. 38, Springer, Cham, Switzerland. 
[168] Silling, S. A., Epton, M., Weckner, O., Xu, J., and Askari, E., 2007, "Peridynamic States and Constitutive Modeling," J. Elasticity, 88(2), pp. 151-184.

[169] Silling, S., and Lehoucq, R., 2010, "Peridynamic Theory of Solid Mechanics," Adv. Appl. Mech., 44(1), pp. 73-166.

[170] Askari, E., Bobaru, F., Lehoucq, R., Parks, M., Silling, S., and Weckner, O., 2008, "Peridynamics for Multiscale Materials Modeling," J. Phys.: Conf. Ser., 125(1), p. 012078

[171] Silling, S. A., and Askari, E., 2005, "A Meshfree Method Based on the Peridynamic Model of Solid Mechanics," Comput. Struct., 83(17), pp. 1526-1535.

[172] Parks, M. L., Lehoucq, R. B., Plimpton, S. J., and Silling, S. A., 2008, "Implementing Peridynamics Within a Molecular Dynamics Code," Comput. Phys. Commun., 179(11), pp. 777-783.

[173] Leyendecker, S., Ober-Blöbaum, S., Marsden, J. E., and Ortiz, M., 2010, "Discrete Mechanics and Optimal Control for Constrained Systems," Optim. Control Appl. Methods, 31(6), pp. 505-528.

[174] Ferretti, M., Madeo, A., dell'Isola, F., and Boisse, P., 2014, "Modeling the Onset of Shear Boundary Layers in Fibrous Composite Reinforcements by Second-Gradient Theory," Z. Angew. Math. Phys., 65(3), pp. 587-612.

[175] Andreaus, U., dell'Isola, F., and Porfiri, M., 2004, "Piezoelectric Passive Distributed Controllers for Beam Flexural Vibrations," J. Vib. Control, 10(5), pp. 625-659.

[176] Maurini, C., Pouget, J., and dell'Isola, F., 2006, "Extension of the Euler-Bernoulli Model of Piezoelectric Laminates to Include 3D Effects Via a Mixed Approach," Comput. Struct., 84(22), pp. 1438-1458.

[177] dell'Isola, F., Maurini, C., and Porfiri, M., 2004, "Passive Damping of Beam Vibrations Through Distributed Electric Networks and Piezoelectric Transducers: Prototype Design and Experimental Validation," Smart Mater. Struct., 13(2), p. 299.

[178] Gantzounis, G., Serra-Garcia, M., Homma, K., Mendoza, J., and Daraio, C., 2013, "Granular Metamaterials for Vibration Mitigation," J. Appl. Phys., 114(9), p. 093514

[179] Alessandroni, S., Andreaus, U., dell'Isola, F., and Porfiri, M., 2005, "A Passive Electric Controller for Multimodal Vibrations of Thin Plates," Comput. Struct., 83(15), pp. 1236-1250.

[180] Bailey, T., and Ubbard, J. E., 1985, "Distributed Piezoelectric-Polymer Active Vibration Control of a Cantilever Beam," J. Guid. Control Dyn., 8(5), pp. 605-611.

[181] Behrens, S., Fleming, A. J., and Moheimani, S. O. R., 2003, "A Broadband Controller for Shunt Piezoelectric Damping of Structural Vibration," Smart Mater. Struct., 12(1), p. 18.

[182] Corr, L. R., and Clark, W. W., 2003, "A Novel Semi-Active Multi-Modal Vibration Control Law for a Piezoceramic Actuator," ASME J. Vib. Acoust., 125(2), pp. 214-222.

[183] Dimitriadis, E. K., Fuller, C. R., and Rogers, C. A., 1991, "Piezoelectric Actuators for Distributed Vibration Excitation of Thin Plates," ASME J. Vib. Acoust., 113(1), pp. 100-107.

[184] Hollkamp, J. J., 1994, "Multimodal Passive Vibration Suppression With Piezoelectric Materials and Resonant Shunts,” J. Intell. Mater. Syst. Struct., 5(1), pp. 49-57.

[185] Lallart, M., Lefeuvre, É., Richard, C., and Guyomar, D., 2008, "Self-Powered Circuit for Broadband, Multimodal Piezoelectric Vibration Control," Sens. Actuators A, 143(2), pp. 377-382.

[186] Pipkin, A., 1981, "Plane Traction Problems for Inextensible Networks," Q. J. Mech. Appl. Math., 34(4), pp. 415-429.

[187] Rivlin, R., 1997, "Plane Strain of a Net Formed by Inextensible Cords," Collected Papers of RS Rivlin, Springer, New York, pp. 511-534

[188] D’Agostino, M. V., Giorgio, I., Greco, L., Madeo, A., and Boisse, P., 2015, "Continuum and Discrete Models for Structures Including (Quasi-) Inextensible Elasticae With a View to the Design and Modeling of Composite Reinforcements," Int. J. Solids Struct., 59, pp. 1-17.

[189] dell'Isola, F., D'Agostino, M. V., Madeo, A., Boisse, P., and Steigmann, D., "Minimization of Shear Energy in Two Dimensional Continua With Two Orthogonal Families of Inextensible Fibers: The Case of Standard Bias Extension Test," J. Elasticity, epub.

[190] dell'Isola, F., Giorgio, I., and Andreaus, U., 2015, "Elastic Pantographic 2D Lattices: A Numerical Analysis on Static Response and Wave Propagation," Proc. Est. Acad. Sci., 64(3), pp. 219-225.

[191] Descamps, B., 2014, Computational Design of Lightweight Structures: Form Finding and Optimization, Wiley, Weinheim, Germany.

[192] Dell'Isola, F., Della Corte, A., Greco, L., and Luongo, A., "Plane Bias Extension Test for a Continuum With Two Inextensible Families of Fibers: A Variational Treatment With Lagrange Multipliers and a Perturbation Solution," Int. J. Solids Struct. (in press).

[193] dell'Isola, F., and Steigmann, D., 2015, "A Two-Dimensional GradientElasticity Theory for Woven Fabrics,” J. Elasticity, 118(1), pp. 113-125.

[194] Hamila, N., and Boisse, P., 2013, "Tension Locking in Finite-Element Analyses of Textile Composite Reinforcement Deformation," C. R. Méc., 341(6), pp. $508-519$

[195] Hamila, N., and Boisse, P., 2013, "Locking in Simulation of Composite Reinforcement Deformations. Analysis and Treatment," Composites, Part A, 53, pp. $109-117$.

[196] Federico, S., 2010, "On the Linear Elasticity of Porous Materials," Int. J. Mech. Sci., 52(2), pp. 175-182.

[197] Hollister, S. J., 2005, "Porous Scaffold Design for Tissue Engineering," Nat. Mater., 4(7), pp. 518-524.
[198] Serra, F., Vishnubhatla, K. C., Buscaglia, M., Cerbino, R., Osellame, R., Cerullo, G., and Bellini, T., 2011, "Topological Defects of Nematic Liquid Crystals Confined in Porous Networks," Soft Matter, 7(22), pp. 10945-10950.

[199] Araki, T., Buscaglia, M., Bellini, T., and Tanaka, H., 2011, "Memory and Topological Frustration in Nematic Liquid Crystals Confined in Porous Materials," Nat. Mater., 10(4), pp. 303-309.

[200] Andreaus, U., and Colloca, M., 2009, "Prediction of Micromotion Initiation of an Implanted Femur Under Physiological Loads and Constraints Using the Finite Element Method,” Proc. Inst. Mech. Eng, Part H, 223, pp. 589-605.

[201] Andreaus, U., Colloca, M., and Iacoviello, D., 2013, Modeling of Trabecular Architecture as Result of an Optimal Control Procedure (Lecture Notes in Computational Vision and Biomechanics), Vol. 4, Springer, Dordrecht.

[202] Andreaus, U., Colloca, M., Iacoviello, D., and Pignataro, M., 2011, "OptimalTuning PID Control of Adaptive Materials for Structural Efficiency," Struct. Multidiscip. Optim., 43(1), pp. 43-59.

[203] Andreaus, U., Giorgio, I., and Lekszycki, T., 2014, “A 2-D Continuum Model of a Mixture of Bone Tissue and Bio-Resorbable Material for Simulating Mass Density Redistribution Under Load Slowly Variable in Time," Z. Angew. Math. Mech./J. Appl. Math. Mech., 94(12), pp. 978-1000.

[204] Park, J.-G., Ye, Q., Topp, E. M., Lee, C. H., Kostoryz, E. L., Misra, A., and Spencer, P., 2009, "Dynamic Mechanical Analysis and Esterase Degradation of Dentin Adhesives Containing a Branched Methacrylate," J. Biomed. Mater. Res., Part B, 91(1), pp. 61-70.

[205] Andreaus, U., Giorgio, I., and Madeo, A., 2014, "Modeling of the Interaction Between Bone Tissue and Resorbable Biomaterial as Linear Elastic Materials With Voids," Z. Angew. Math. Phys., 66(1), pp. 209-237.

[206] Ganghoffer, J.-F., 2012, "A Contribution to the Mechanics and Thermodynamics of Surface Growth. Application to Bone External Remodeling," Int. J. Eng. Sci., 50(1), pp. 166-191.

[207] Giorgio, I., Andreaus, U., and Madeo, A., 2014, "The Influence of Different Loads on the Remodeling Process of a Bone and Bio-Resorbable Material Mixture With Voids," Continuum Mech. Thermodyn., epub.

[208] Laurent, C., Durville, D., Vaquette, C., Rahouadj, R., and Ganghoffer, J., 2013, "Computer-Aided Tissue Engineering: Application to the Case of Anterior Cruciate Ligament Repair,” Biomech. Cells Tissues, 9(1), pp. 1-44.

[209] Laurent, C., Durville, D., Mainard, D., Ganghoffer, J.-F., and Rahouadj, R., 2012, "Designing a New Scaffold for Anterior Cruciate Ligament Tissue Engineering," J. Mech. Behav. Biomed. Mater., 12(1), pp. 184-196.

[210] Laurent, C., Durville, D., Wang, X., Ganghoffer, J.-F., and Rahouadj, R., 2010, "Designing a New Scaffold for Anterior Cruciate Ligament Tissue Engineering," Comput. Methods Biomech. Biomed. Eng., 13(S1), pp. 87-88.

[211] Misra, A., Spencer, P., Marangos, O., Wang, Y., and Katz, J. L., 2005, "Parametric Study of the Effect of Phase Anisotropy on the Micromechanical Behaviour of Dentin-Adhesive Interfaces," J. R. Soc. Interface, 2(3), pp. 145-157.

[212] Spencer, P., Ye, Q., Park, J., Topp, E. M., Misra, A., Marangos, O., Wang, Y., Bohaty, B. S., Singh, V., Sene, F., Eslick, J., Camarda, K., and Katz, J. L., 2010, "Adhesive/Dentin Interface: The Weak Link in the Composite Restoration," Ann. Biomed. Eng., 38(6), pp. 1989-2003.

[213] Steigmann, D. J., and dell'Isola, D., "Mechanical Response of Fabric Sheets to Three-Dimensional Bending, Twisting, and Stretching," Acta Mech. Sin., 31(3), pp. 373-382.

[214] Ye, Q., Spencer, P., Wang, Y., and Misra, A., 2007, "Relationship of Solvent to the Photopolymerization Process, Properties, and Structure in Model Dentin Adhesives," J. Biomed. Mater. Res., Part A, 80(2), pp. 342-350.

[215] Hu, L., Pasta, M., Mantia, F. L., Cui, L., Jeong, S., Deshazer, H. D., Choi, J. W., Han, S. M., and Cui, Y., 2010, "Stretchable, Porous, and Conductive Energy Textiles," Nano Lett., 10(2), pp. 708-714.

[216] Piccardo, G., Ranzi, G., and Luongo, A., 2014, "A Complete Dynamic Approach to the Generalized Beam Theory Cross-Section Analysis Including Extension and Shear Modes," Math. Mech. Solids, 19(8), pp. 900-924.

[217] Piccardo, G., and Tubino, F., 2012, "Dynamic Response of Euler-Bernoulli Beams to Resonant Harmonic Moving Loads," Struct. Eng. Mech., 44(5), pp. 681-704.

[218] Luongo, A., Zulli, D., and Piccardo, G., 2007, "A Linear Curved-Beam Model for the Analysis of Galloping in Suspended Cables," J. Mech. Mater. Struct., 2(4), pp. 675-694.

[219] Altenbach, H., Bîrsan, M., and Eremeyev, V. A., 2012, "On a Thermodynamic Theory of Rods With Two Temperature Fields," Acta Mech., 223(8), pp. $1583-1596$.

[220] Luongo, A., and Piccardo, G., 1998, "Non-Linear Galloping of Sagged Cables in 1:2 Internal Resonance," J. Sound Vib., 214(5), pp. 915-940.

[221] Luongo, A., Zulli, D., and Piccardo, G., 2008, "Analytical and Numerical Approaches to Nonlinear Galloping of Internally Resonant Suspended Cables," J. Sound Vib., 315(3), pp. 375-393.

[222] Luongo, A., Rega, G., and Vestroni, F., 1984, "Planar Non-Linear Free Vibrations of an Elastic Cable," Int. J. Nonlinear Mech., 19(1), pp. 39-52.

[223] Luongo, A., 1996, "Perturbation Methods for Nonlinear Autonomous Discrete-Time Dynamical Systems," Nonlinear Dyn., 10(4), pp. 317-331.

[224] Liu, W. K., Park, H. S., Qian, D., Karpov, E. G., Kadowaki, H., and Wagner, G. J., 2006, "Bridging Scale Methods for Nanomechanics and Materials," Comput. Methods Appl. Mech. Eng., 195(13), pp. 1407-1421.

[225] Miehe, C., Schröder, J., and Schotte, J., 1999, "Computational Homogenization Analysis in Finite Plasticity Simulation of Texture Development in Polycrystalline Materials,” Comput. Methods Appl. Mech. Eng., 171(3), pp. $387-418$. 
[226] Brun, M., Lopez-Pamies, O., and Castaneda, P. P., 2007, "Homogenization Estimates for Fiber-Reinforced Elastomers With Periodic Microstructures," Int. J. Solids Struct., 44(18), pp. 5953-5979.

[227] Milton, G., 1986, "Modelling the Properties of Composites by Laminates," Homogenization and Effective Moduli of Materials and Media, Springer, New York, pp. 150-174

[228] Dos Reis, F., and Ganghoffer, J., 2012, "Equivalent Mechanical Properties of Auxetic Lattices From Discrete Homogenization," Comput. Mater. Sci., 51(1), pp. 314-321

[229] Dos Reis, F., and Ganghoffer, J.-F., 2011, "Construction of Micropolar Continua From the Homogenization of Repetitive Planar Lattices," Mechanics of Generalized Continua, Springer, New York, pp. 193-217.

[230] Ladeveze, P., and Nouy, A., 2003, “On a Multiscale Computational Strategy With Time and Space Homogenization for Structural Mechanics," Comput. Methods Appl. Mech. Eng., 192(28), pp. 3061-3087.

[231] Federico, S., Grillo, A., and Herzog, W., 2004, "A Transversely Isotropic Composite With a Statistical Distribution of Spheroidal Inclusions: A Geometrical Approach to Overall Properties," J. Mech. Phys. Solids, 52(10), pp. 2309-2327.

[232] Goda, I., Assidi, M., Belouettar, S., and Ganghoffer, J., 2012, “A Micropolar Anisotropic Constitutive Model of Cancellous Bone From Discrete Homogenization," J. Mech. Behav. Biomed. Mater., 16, pp. 87-108.

[233] Ebinger, T., Steeb, H., and Diebels, S., 2005, "Modeling Macroscopic Extended Continua With the Aid of Numerical Homogenization Schemes," Comput. Mater. Sci., 32(3), pp. 337-347.

[234] Ober-Blöbaum, S., Junge, O., and Marsden, J. E., 2011, "Discrete Mechanics and Optimal Control: An Analysis," ESAIM: Control Optim. Calculus Var., 17(2), pp. 322-352.

[235] Luongo, A., Rega, G., and Vestroni, F., 1986, "On Nonlinear Dynamics of Planar Shear Indeformable Beams,” ASME J. Appl. Mech., 53(3), pp. 619-624.

[236] Bîrsan, M., Altenbach, H., Sadowski, T., Eremeyev, V., and Pietras, D., 2012, "Deformation Analysis of Functionally Graded Beams by the Direct Approach," Composites, Part B, 43(3), pp. 1315-1328.

[237] Mei, C. C., and Vernescu, B., 2010, Homogenization Methods for Multiscale Mechanics, World Scientific, Singapore.

[238] Madeo, A., Neff, P., Ghiba, I.-D., Placidi, L., and Rosi, G., 2013, "Wave Propagation in Relaxed Micromorphic Continua: Modeling Metamaterials With Frequency Band-Gaps," Continuum Mech. Thermodyn., 27(4), pp. 551-570.

[239] Berezovski, A., Giorgio, I., and Della Corte, A., 2015, "Interfaces in Micromorphic Materials: Wave Transmission and Reflection With Numerical Simulations," Math. Mech. Solids, epub.

[240] Madeo, A., Della Corte, A., Greco, L., and Neff, P., "Wave Propagation in Pantographic 2D Lattices With Internal Discontinuities," Proc. Est. Acad. Sci., epub.

[241] Seppecher, P., Alibert, J.-J., and dell'Isola, F., 2011, "Linear Elastic Trusses Leading to Continua With Exotic Mechanical Interactions," J. Phys.: Conf. Ser., 319(1), p. 012018

[242] Giorgio, I., Culla, A., and Del Vescovo, D., 2009, "Multimode Vibration Control Using Several Piezoelectric Transducers Shunted With a Multiterminal Network," Arch. Appl. Mech., 79(9), pp. 859-879.

[243] Moheimani, S. O. R., 2003, "A Survey of Recent Innovations in Vibration Damping and Control Using Shunted Piezoelectric Transducers," IEEE Trans. Control Syst. Technol., 11(4), pp. 482-494.

[244] Porfiri, M., dell'Isola, F., and Mascioli, F., 2004, "Circuit Analog of a Beam and Its Application to Multimodal Vibration Damping, Using Piezoelectric Transducers,” Int. J. Circuit Theory Appl., 32(4), pp. 167-198.

[245] Eremeev, V., Freidin, A., and Sharipova, L., 2003, "Nonuniqueness and Stability in Problems of Equilibrium of Elastic Two-Phase Bodies," Dokl. Phys., 48(7), pp. 359-363.

[246] Yeremeyev, V., Freidin, A., and Sharipova, L., 2007, "The Stability of the Equilibrium of Two-Phase Elastic Solids," J. Appl. Math. Mech., 71(1), pp. 61-84.

[247] Rizzi, N., Varano, V., and Gabriele, S., 2013, "Initial Postbuckling Behavior of Thin-Walled Frames Under Mode Interaction," Thin-Walled Struct., 68, pp. 124-134.

[248] Rizzi, N., and Varano, V., 2011, "On the Postbuckling Analysis of ThinWalled Frames," 13th International Conference On Civil, Structural And Environmental Engineering Computing (CC2011), Chania, Crete, Greece, Sept. 6-9, Paper No. 43.

[249] Rizzi, N., and Varano, V., 2011, "The Effects of Warping on the Postbuckling Behaviour of Thin-Walled Structures," Thin-Walled Struct., 49(9), pp. 1091-1097.

[250] Pignataro, M., Ruta, G., Rizzi, N., and Varano, V., 2010, "Effects of Warping Constraints and Lateral Restraint on the Buckling of Thin-Walled Frames," ASME Paper No. IMECE2009-12254.

[251] Pignataro, M., Rizzi, N., Ruta, G., and Varano, V., 2009, "The Effects of Warping Constraints on the Buckling of Thin-Walled Structures," J. Mech. Mater. Struct., 4(10), pp. 1711-1727.

[252] Ruta, G., Varano, V., Pignataro, M., and Rizzi, N., 2008, “A Beam Model for the Flexural-Torsional Buckling of Thin-Walled Members With Some Applications," Thin-Walled Struct., 46(7-9), pp. 816-822.

[253] Pignataro, M., Rizzi, N., and Luongo, A., 1991, Stability, Bifurcation, and Postcritical Behaviour of Elastic Structures, Elsevier, Amsterdam.

[254] Luongo, A., 2001, "Mode Localization in Dynamics and Buckling of Linear Imperfect Continuous Structures," Nonlinear Dyn., 25(1-3), pp. 133-156.

[255] Luongo, A., and Piccardo, G., 2005, "Linear Instability Mechanisms for Coupled Translational Galloping," J. Sound Vib., 288(4), pp. 1027-1047.
[256] Luongo, A., and Zulli, D., 2012, "Dynamic Instability of Inclined Cables Under Combined Wind Flow and Support Motion," Nonlinear Dyn., 67(1), pp. 71-87.

[257] Luongo, A., and Zulli, D., 2014, "Aeroelastic Instability Analysis of NESControlled Systems Via a Mixed Multiple Scale/Harmonic Balance Method," J. Vib. Control, 20(13), pp. 1985-1998.

[258] Luongo, A., 2010, "A Unified Perturbation Approach to Static/Dynamic Coupled Instabilities of Nonlinear Structures," Thin-Walled Struct., 48(10), pp. 744-751.

[259] Di Egidio, A., Luongo, A., and Paolone, A., 2007, "Linear and Non-Linear Interactions Between Static and Dynamic Bifurcations of Damped Planar Beams," Int. J. Nonlinear Mech., 42(1), pp. 88-98.

[260] Vestroni, F., Luongo, A., and Pasca, M., 1995, "Stability and Control of Transversal Oscillations of a Tethered Satellite System," Appl. Math. Comput., 70(2), pp. 343-360.

[261] Knight, J., Page, T., and Chandler, H., 1991, "Thermal Instability of the Microstructure and Surface Mechanical Properties of Hydrogenated Amorphous Carbon Films," Surf. Coat. Technol., 49(1), pp. 519-529.

[262] Ma, E., 2003, "Nanocrystalline Materials: Controlling Plastic Instability," Nat. Mater., 2(1), pp. 7-8.

[263] Konkova, T., Mironov, S., Korznikov, A., and Semiatin, S., 2010, "Microstructure Instability in Cryogenically Deformed Copper," Scr. Mater., 63(9), pp. 921-924.

[264] Zhu, H., Maruyama, K., Seo, D., and Au, P., 2006, "Effect of Initial Microstructure on Microstructural Instability and Creep Resistance of XD TiAl Alloys," Metall. Mater. Trans. A, 37(10), pp. 3149-3159.

[265] Lipson, H., and Kurman, M., 2013, Fabricated: The New World of 3D Printing, Wiley, Weinheim, Germany.

[266] Hockaday, L., Kang, K., Colangelo, N., Cheung, P., Duan, B., Malone, E., Wu, J., Girardi, L., Bonassar, L., Lipson, H., Chu, C. C., and Butcher, J. T., 2012, "Rapid 3D Printing of Anatomically Accurate and Mechanically Heterogeneous Aortic Valve Hydrogel Scaffolds," Biofabrication, 4(3), p. 035005.

[267] Greiner, A., and Wendorff, J. H., 2007, "Electrospinning: A Fascinating Method for the Preparation of Ultrathin Fibers," Angew. Chem. Int. Ed., 46(30), pp. 5670-5703.

[268] Sill, T. J., and von Recum, H. A., 2008, "Electrospinning: Applications in Drug Delivery and Tissue Engineering," Biomaterials, 29(13), pp. 1989-2006.

[269] Bhardwaj, N., and Kundu, S. C., 2010, "Electrospinning: A Fascinating Fiber Fabrication Technique," Biotechnol. Adv., 28(3), pp. 325-347.

[270] Di Camillo, D., Fasano, V., Ruggieri, F., Santucci, S., Lozzi, L., Camposeo, A., and Pisignano, D., 2013, "Near-Field Electrospinning of Conjugated Polymer Light-Emitting Nanofibers," Nanosc., 5, pp. 11637-11642.

[271] Di Camillo, D., Ruggieri, F., Santucci, S., and Lozzi, L., 2012, "N-Doped $\mathrm{TiO}_{2}$ Nanofibers Deposited by Electrospinning," J. Phys. Chem. C, 116(34), pp. 18427-18431.

[272] Dell'Erba, R., dell'Isola, F., and Rotoli, G., 1999, "The Influence of the Curvature Dependence of the Surface Tension on the Geometry of Electrically Charged Menisci," Continuum Mech. Thermodyn., 11(2), pp. 89-105.

[273] Agarwal, S., Wendorff, J. H., and Greiner, A., 2009, "Progress in the Field of Electrospinning for Tissue Engineering Applications," Adv. Mater., 21(32-33), pp. 3343-3351.

[274] Beachley, V., Kasyanov, V., Nagy-Mehesz, A., Norris, R., Ozolanta, I., Kalejs, M., Stradins, P., Baptista, L., da Silva, K., Grainjero, J., Wen, X., and Mironov, V., 2014, "The Fusion of Tissue Spheroids Attached to Pre-Stretched Electrospun Polyurethane Scaffolds," J. Tissue Eng., 5, p. 2041731414556561.

[275] Yasuda, H., and Yang, J., 2015, "Reentrant Origami-Based Metamaterials With Negative Poisson's Ratio and Bistability," Phys. Rev. Lett., 114(18), p. 185502 .

[276] Boutin, C., and Becot, F. X., 2015, "Theory and Experiments on PoroAcoustics With Inner Resonators," Wave Motion, 54, pp. 76-99.

[277] Boutin, L. D. M. C., Schwan, "Depolarization of Mechanical Waves by Anisotropic Metasurface," J. Appl. Phys., 117(6), p. 064902.

[278] Boutin, C., and Auriault, J., 1993, "Rayleigh Scattering in Elastic Composite Materials," Int. J. Eng. Sci., 31(12), pp. 1669-1689.

[279] Boutin, C., Rallu, A., and Hans, S., 2012, "Large Scale Modulation of High Frequency Acoustic Waves in Periodic Porous Media," J. Acoust. Soc. Am., 132(6), pp. 3622-3636.

[280] Boutin, C., Royer, P., and Auriault, J., 1998, "Acoustic Absorption of Porous Surfacing With Dual Porosity," Int. J. Solids Struct., 35(34), pp. 4709-4737.

[281] Chesnais, C., Hans, S., and Boutin, C., 2007, "Wave Propagation and Diffraction in Discrete Structures: Effect of Anisotropy and Internal Resonance," PAMM, 7(1), p. 1090.

[282] Fokin, V., Ambati, M., Sun, C., and Zhang, X., 2007, "Method for Retrieving Effective Properties of Locally Resonant Acoustic Metamaterials," Phys. Rev. B, 76(14), p. 144302.

[283] Wang, P., Casadei, F., Shan, S., Weaver, J. C., and Bertoldi, K., 2014, "Harnessing Buckling to Design Tunable Locally Resonant Acoustic Metamaterials," Phys. Rev. Lett., 113(1), p. 014301.

[284] Altenbach, H., Eremeyev, V. A., and Morozov, N. F., 2013, "Mechanical Properties of Materials Considering Surface Effects," IUTAM Symposium on Surface Effects in the Mechanics of Nanomaterials and Heterostructures, Beijing, Aug. 8-12, pp. 105-115.

[285] Nesterenko, V., Daraio, C., Herbold, E., and Jin, S., 2005, “Anomalous Wave Reflection at the Interface of Two Strongly Nonlinear Granular Media," Phys. Rev. Lett., 95(15), p. 158702. 
[286] Eremeyev, V. A., 2015, "On Effective Properties of Materials at the Nanoand Microscales Considering Surface Effects," Acta Mech., epub.

[287] Cuenot, S., Frétigny, C., Demoustier-Champagne, S., and Nysten, B., 2004, "Surface Tension Effect on the Mechanical Properties of Nanomaterials Measured by Atomic Force Microscopy," Phys. Rev. B, 69(16), p. 165410.

[288] Chen, C., Shi, Y., Zhang, Y., Zhu, J., and Yan, Y., 2006, "Size Dependence of Young's Modulus in ZnO Nanowires," Phys. Rev. Lett., 96(7), p. 075505.

[289] Liu, X., Luo, J., and Zhu, J., 2006, "Size Effect on the Crystal Structure of Silver Nanowires," Nano Lett., 6(3), pp. 408-412.

[290] Jing, G. Y., Duan, H. L., Sun, X. M., Zhang, Z. S., Xu, J., Li, Y. D., Wang, J. X., and Yu, D. P., 2006, "Surface Effects on Elastic Properties of Silver Nanowires: Contact Atomic-Force Microscopy," Phys. Rev. B, 73(23), p. 235409.

[291] He, J., and Lilley, C. M., 2008, "Surface Effect on the Elastic Behavior of Static Bending Nanowires," Nano Lett., 8(7), pp. 1798-1802.

[292] Greer, J. R., and De Hosson, J. T. M., 2011, "Plasticity in Small-Sized Metallic Systems: Intrinsic Versus Extrinsic Size Effect,” Prog. Mater. Sci., 56(6), pp. 654-724.

[293] Greer, J. R., and Nix, W. D., 2005, "Size Dependence of Mechanical Properties of Gold at the Sub-Micron Scale," Appl. Phys. A, 80(8), pp. 1625-1629.

[294] Özgür, Ü., Alivov, Y. I., Liu, C., Teke, A., Reshchikov, M., Doğan, S., Avrutin, V., Cho, S.-J., and Morkoc, H., 2005, "A Comprehensive Review of ZnO Materials and Devices," J. Appl. Phys., 98(4), p. 041301.

[295] Bhushan, B., ed., 2007, Handbook Springer of Nanotechnology, Springer, Berlin.

[296] Melechko, A. V., Merkulov, V. I., McKnight, T. E., Guillorn, M., Klein, K. L., Lowndes, D. H., and Simpson, M. L., 2005, "Vertically Aligned Carbon Nanofibers and Related Structures: Controlled Synthesis and Directed Assembly," J. Appl. Phys., 97(4), p. 041301.

[297] Grimm, S., Giesa, R., Sklarek, K., Langner, A., Gosele, U., Schmidt, H.-W., and Steinhart, M., 2008, "Nondestructive Replication of Self-Ordered Nanoporous Alumina Membranes Via Cross-Linked Polyacrylate Nanofiber Arrays," Nano Lett., 8(7), pp. 1954-1959.

[298] Ma, X., Liu, A., Xu, H., Li, G., Hu, M., and Wu, G., 2008, "A Large-ScaleOriented $\mathrm{ZnO}$ Rod Array Grown on a Glass Substrate Via an In Situ Deposition Method and Its Photoconductivity," Mater. Res. Bull., 43(8), pp. 2272-2277.

[299] Tan, L. K., Kumar, M. K., An, W. W., and Gao, H., 2010, "Transparent, Well-Aligned $\mathrm{TiO}_{2}$ Nanotube Arrays With Controllable Dimensions on Glass Substrates for Photocatalytic Applications," ACS Appl. Mater. Interfaces, 2(2), pp. 498-503.

[300] Hutchens, S. B., Needleman, A., and Greer, J. R., 2011, "Analysis of Uniaxial Compression of Vertically Aligned Carbon Nanotubes," J. Mech. Phys. Solids, 59(10), pp. 2227-2237.

[301] Spinelli, P., Verschuuren, M., and Polman, A., 2012, "Broadband Omnidirectional Antireflection Coating Based on Subwavelength Surface Mie Resonators," Nat. Commun., 3, p. 692.

[302] Naumenko, K., and Eremeyev, V. A., 2014, "A Layer-Wise Theory for Laminated Glass and Photovoltaic Panels," Compos. Struct., 112, pp. 283-291.

[303] Kang, X., Zi, W.-W., Xu, Z.-G., and Zhang, H.-L., 2007, "Controlling the Micro/Nanostructure of Self-Cleaning Polymer Coating," Appl. Surf. Sci., 253(22), pp. 8830-8834.

[304] Rios, P., Dodiuk, H., Kenig, S., McCarthy, S., and Dotan, A., 2007, "Transparent Ultra-Hydrophobic Surfaces," J. Adhes. Sci. Technol., 21(5-6), pp. $399-408$

[305] Sanjay, S. L., Annaso, B. G., Chavan, S. M., and Rajiv, S. V., 2012, "Recent Progress in Preparation of Superhydrophobic Surfaces: A Review," J. Surf. Eng. Mater. Adv. Technol., 2(2), pp. 76-94.

[306] Dastjerdi, R., and Montazer, M., 2010, "A Review on the Application of Inorganic Nano-Structured Materials in the Modification of Textiles: Focus on Anti-Microbial Properties," Colloids Surf. B, 79(1), pp. 5-18.

[307] Contreras, C. B., Chagas, G., Strumia, M. C., and Weibel, D. E., 2014, "Permanent Superhydrophobic Polypropylene Nanocomposite Coatings by a Simple One-Step Dipping Process," Appl. Surf. Sci., 307, pp. 234-240.

[308] Tian, X., Yi, L., Meng, X., Xu, K., Jiang, T., and Lai, D., 2014, "Superhydrophobic Surfaces of Electrospun Block Copolymer Fibers With Low Content of Fluorosilicones," Appl. Surf. Sci., 307, pp. 566-575.

[309] Heinonen, S., Huttunen-Saarivirta, E., Nikkanen, J.-P., Raulio, M., Priha, O., Laakso, J., Storgårds, E., and Levänen, E., 2014, “Antibacterial Properties and Chemical Stability of Superhydrophobic Silver-Containing Surface Produced by Sol-Gel Route," Colloids Surf. A, 453, pp. 149-161.

[310] Escobar, A. M., and Llorca-Isern, N., 2014, "Superhydrophobic Coating Deposited Directly on Aluminum," Appl. Surf. Sci., 305, pp. 774-782.

[311] Li, J., Zheng, W., Zeng, W., Zhang, D., and Peng, X., 2014, "Structure, Properties and Application of a Novel Low-Glossed Waterborne Polyurethane," Appl. Surf. Sci., 307, pp. 255-262.

[312] Ganesh, V. A., Raut, H. K., Nair, A. S., and Ramakrishna, S., 2011, "A Review on Self-Cleaning Coatings," J. Mater. Chem., 21(41), pp. 16304-16322.

[313] Liu, K., and Jiang, L., 2012, "Bio-Inspired Self-Cleaning Surfaces," Annu. Rev. Mater. Res., 42, pp. 231-263.

[314] Longley, W. R., and Name, R. G. V., eds., 1928, The Collected Works of J. Willard Gibbs, PHD., LL.D. I Thermodynamics, Longmans, New York.

[315] Rowlinson, J. S., and Widom, B., 2003, Molecular Theory of Capillarity, Dover, New York

[316] de Gennes, P. G., Brochard-Wyart, F., and Quéré, D., 2004, Capillarity and Wetting Phenomena: Drops, Bubbles, Pearls, Waves, Springer, New York.
[317] Gurtin, M. E., and Murdoch, A. I., 1975, "A Continuum Theory of Elastic Material Surfaces," Arch. Ration. Mech. Anal., 57(4), pp. 291-323.

[318] Gurtin, M. E., and Murdoch, A. I., 1975, "Addenda to Our Paper. A Continuum Theory of Elastic Material Surfaces," Arch. Ration. Mech. Anal., 59(4), pp. 389-390.

[319] Duan, H. L., Wang, J., and Karihaloo, B. L., 2008, "Theory of Elasticity at the Nanoscale," Adv. Appl. Mech., 42, pp. 1-68.

[320] Wang, J., Huang, Z., Duan, H., Yu, S., Feng, X., Wang, G., Zhang, W., and Wang, T., 2011, "Surface Stress Effect in Mechanics of Nanostructured Materials," Acta Mech. Solida Sin., 24(1), pp. 52-82.

[321] Javili, A., McBride, A., and Steinmann, P., 2012, "Thermomechanics of Solids With Lower-Dimensional Energetics: On the Importance of Surface, Interface, and Curve Structures at the Nanoscale. A Unifying Review," ASME Appl. Mech. Rev., 65, p. 010802.

[322] Wang, J., Duan, H. L., Huang, Z. P., and Karihaloo, B. L., 2006, “A Scaling Law for Properties of Nano-Structured Materials," Proc. R. Soc. A, 462(2069), pp. 1355-1363.

[323] Steigmann, D. J., and Ogden, R. W., 1999, "Elastic Surface-Substrate Interactions," Proc. R. Soc. A, 455(1982), pp. 437-474.

[324] Javili, A., and Steinmann, P., 2010, "On Thermomechanical Solids With Boundary Structures," Int. J. Solids Struct., 47(24), pp. 3245-3253.

[325] Povstenko, Y., 2013, "Mathematical Modeling of Phenomena Caused by Surface Stresses in Solids," Surface Effects in Solid Mechanics, H. Altenbach and N. F. Morozov, eds., Springer, Berlin, pp. 135-153.

[326] Rubin, M., and Benveniste, Y., 2004, "A Cosserat Shell Model for Interphases in Elastic Media," J. Mech. Phys. Solids, 52(5), pp. 1023-1052.

[327] Kim, C. I., Schiavone, P., and Ru, C.-Q., 2011, "Effect of Surface Elasticity on an Interface Crack in Plane Deformations," Proc. R. Soc. A, 467(2136), pp. 3530-3549.

[328] Kim, C., Ru, C., and Schiavone, P., 2013, "A Clarification of the Role of Crack-Tip Conditions in Linear Elasticity With Surface Effects," Math. Mech. Solids, 18(1), pp. 59-66.

[329] Schiavone, P., and Ru, C.-Q., 2009, "Solvability of Boundary Value Problems in a Theory of Plane-Strain Elasticity With Boundary Reinforcement," Int. J. Eng. Sci., 47(11), pp. 1331-1338.

[330] Javili, A., McBride, A., Steinmann, P., and Reddy, B., 2012, "Relationships Between the Admissible Range of Surface Material Parameters and Stability of Linearly Elastic Bodies," Philos. Mag., 92(28-30), pp. 3540-3563.

[331] Guo, J. G., and Zhao, Y. P., 2005 "The Size-Dependent Elastic Properties of Nanofilms With Surface Effects," J. Appl. Phys., 98(7), p. 074306.

[332] Wang, Z. Q., Zhao, Y.-P., and Huang, Z.-P., 2010, "The Effects of Surface Tension on the Elastic Properties of Nano Structures," Int. J. Eng. Sci., 48(2), pp. $140-150$.

[333] Eremeyev, V. A., Altenbach, H., and Morozov, N. F., 2009, "The Influence of Surface Tension on the Effective Stiffness of Nanosize Plates," Dokl. Phys., 54(2), pp. 98-100.

[334] Altenbach, H., Eremeyev, V. A., and Morozov, N. F., 2012, "Surface Viscoelasticity and Effective Properties of Thin-Walled Structures at the Nanoscale," Int. J. Eng. Sci., 59(SI), pp. 83-89.

[335] Altenbach, H., and Eremeyev, V. A., 2011, "On the Shell Theory on the Nanoscale With Surface Stresses,” Int. J. Eng. Sci., 49(12), pp. 1294-1301.

[336] Lagowski, J., Gatos, H. C., and Sproles, E. S., 1975, "Surface Stress and Normal Mode of Vibration of Thin Crystals: GaAs," Appl. Phys. Lett., 26(9), pp. 493-495.

[337] Gurtin, M. E., Markenscoff, X., and Thurston, R. N., 1976, "Effect of Surface Stress on Natural Frequency of Thin Crystals," Appl. Phys. Lett., 29(9), pp. 529-530.

[338] Wang, G.-F., and Feng, X.-Q., 2007, "Effects of Surface Elasticity and Residual Surface Tension on the Natural Frequency of Microbeams," Appl. Phys. Lett., 90(23), p. 231904.

[339] Kampshoff, E., Hahn, E., and Kern, K., 1994, "Correlation Between Surface Stress and the Vibrational Shift of CO Chemisorbed on Cu Surfaces," Phys. Rev. Lett., 73(5), pp. 704-707.

[340] Wang, G. F., and Feng, X. Q., 2010, "Effect of Surface Stresses on the Vibration and Buckling of Piezoelectric Nanowires," EPL, 91(5), p. 56007.

[341] Huang, Z., and Wang, J., 2006, "A Theory of Hyperelasticity of Multi-Phase Media With Surface/Interface Energy Effect," Acta Mech., 182(3), pp. 195-210.

[342] Huang, Z., and Sun, L., 2007, "Size-Dependent Effective Properties of a Heterogeneous Material With Interface Energy Effect: From Finite Deformation Theory to Infinitesimal Strain Analysis," Acta Mech., 190(1), pp. 151-163.

[343] Zhu, H. X., Wang, J. X., and Karihaloo, B. L., 2009, "Effects of Surface and Initial Stresses on the Bending Stiffness of Trilayer Plates and Nanofilms," J. Mech. Mater. Struct., 4(3), pp. 589-604.

[344] Huang, Z., and Wang, J., 2012, "Micromechanics of Nanocomposites With Interface Energy Effect," Handbook on Micromechanics and Nanomechanics, S. Li and X.-L. Gao, eds., Pan Stanford Publishing, Stanford, CA, pp. 303-348.

[345] Javili, A., and Steinmann, P., 2009, "A Finite Element Framework for Continua With Boundary Energies. Part I: The Two-Dimensional Case," Comput. Methods Appl. Mech. Eng., 198(27-29), pp. 2198-2208.

[346] Javili, A., and Steinmann, P., 2011, "A Finite Element Framework for Continua With Boundary Energies. Part III: The Thermomechanical Case," Comput. Methods Appl. Mech. Eng., 200(21), pp. 1963-1977.

[347] Javili, A., McBride, A., and Steinmann, P., 2012, "Numerical Modelling of Thermomechanical Solids With Mechanically Energetic (Generalised) Kapitza Interfaces," Comput. Mater. Sci., 65, pp. 542-551. 
[348] Arroyo, M., and Belytschko, T., 2002, "An Atomistic-Based Finite Deformation Membrane for Single Layer Crystalline Films," J. Mech. Phys. Solids, 50(9), pp. 1941-1977.

[349] Sfyris, D., Sfyris, G., and Galiotis, C., 2014, "Curvature Dependent Surface Energy for a Free Standing Monolayer Graphene: Some Closed Form Solutions of the Non-Linear Theory,” Int. J. Nonlinear Mech., 67, pp. 186-197.

[350] Miller, R. E., and Shenoy, V. B., 2000, "Size-Dependent Elastic Properties of Nanosized Structural Elements," Nanotechnology, 11(3), p. 139.

[351] Shenoy, V. B., 2005, "Atomistic Calculations of Elastic Properties of Metallic FCC Crystal Surfaces,” Phys. Rev. B, 71(9), p. 094104.

[352] Ibach, H., 1997, "The Role of Surface Stress in Reconstruction, Epitaxial Growth and Stabilization of Mesoscopic Structures," Surf. Sci. Rep., 29(5), pp. 195-263.

[353] De Gennes, P. G., 1981, "Some Effects of Long Range Forces on Interfacial Phenomena," J. Phys. Lett., 42(16), pp. 377-379.

[354] Seppecher, P., 1996, Les Fluides de Cahn-Hilliard, Mémoire D'habilitation à Diriger des Recherches, Université du Sud Toulon, La Garde, France.

[355] dell'Isola, F., and Seppecher, P., 1997, "Edge Contact Forces and QuasiBalanced Power," Meccanica, 32(1), pp. 33-52.

[356] dell'Isola, F., and Seppecher, P., 1995, "The Relationship Between Edge Contact Forces, Double Forces and Interstitial Working Allowed by the Principle of Virtual Power," C. R. Acad. Sci. Sér. II, 321(8), pp. 303-308

[357] dellIsola, F., Lekszycki, T., Pawlikowski, M., Grygoruk, R., and Greco, L., 2015, "Designing a Light Fabric Metamaterial Being Highly Macroscopically Tough Under Directional Extension: First Experimental Evidence," Z. Angew. Math. Phys., 66(6), pp. 3473-3498.

[358] Giorgio, I., Grygoruk, R., dell'Isola, F., and Steigmann, D. J., 2015, "Pattern Formation in the Three-Dimensional Deformations of Fibered Sheets," Mech. Res. Commun., 69, pp. 164-171.

[359] G. L. B. A. C. M. dell'Isola, F., "Second Gradient Shear Energies for Pantographic 2D Plates: Numerical Simulations Towards Explanation of Experimental Evidence," (in preparation).

[360] Ball, J. M., 1976, "Convexity Conditions and Existence Theorems in Nonlinear Elasticity,” Arch. Ration. Mech. Anal., 63(4), pp. 337-403.
[361] Kim, D.-H., Lu, N., Ma, R., Kim, Y.-S., Kim, R.-H., Wang, S., Wu, J., Won, S. M., Tao, H., Islam, A., Yu, K. J., Kim, T.-i., Chowdhury, R., Ying, M., Xu, L., Li, M., Chung, H.-J., Keum, H., McCormick, M., Liu, P., Zhang, Y.-W., Omenetto, F. G., Huang, Y., Coleman, T., and Rogers, J. A., 2011, "Epidermal Electronics," Science, 333(6044), pp. 838-843.

[362] Arumugam, V., Naresh, M., and Sanjeevi, R., 1994, "Effect of Strain Rate on the Fracture Behaviour of Skin," J. Biosci., 19(3), pp. 307-313.

[363] Elsner, P., Berardesca, E., and Wilhelm, K.-P., 2001, Bioengineering of the Skin: Skin Biomechanics, Vol. 5, Taylor \& Francis, New York.

[364] Geerligs, M., Van Breemen, L., Peters, G., Ackermans, P., Baaijens, F., and Oomens, C., 2011, "in vitro Indentation to Determine the Mechanical Properties of Epidermis," J. Biomech., 44(6), pp. 1176-1181.

[365] Goriely, A., Destrade, M., and Amar, M. B., 2006, "Instabilities in Elastomers and in Soft Tissues,” Q. J. Mech. Appl. Math., 59(4), pp. 615-630.

[366] Lacour, S. P., Jones, J., Wagner, S., Li, T., and Suo, Z., 2005, "Stretchable Interconnects for Elastic Electronic Surfaces," Proc. IEEE, 93(8), pp. 1459-1467.

[367] Pailler-Mattei, C., Bec, S., and Zahouani, H., 2008, "in vivo Measurements of the Elastic Mechanical Properties of Human Skin by Indentation Tests," Med. Eng. Phys., 30(5), pp. 599-606.

[368] Sekitani, T., Noguchi, Y., Hata, K., Fukushima, T., Aida, T., and Someya, T., 2008, "A Rubberlike Stretchable Active Matrix Using Elastic Conductors," Science, 321(5895), pp. 1468-1472.

[369] Rey, T., Le Cam, J.-B., Chagnon, G., Favier, D., Rebouah, M., Razan, F., Robin, E., Didier, P., Heller, L., Faure, S., and Janouchova, K., 2014, "An Original Architectured NiTi Silicone Rubber Structure for Biomedical Applications," Mater. Sci. Eng. C, 45, pp. 184-190.

[370] Galilei, G., 1894, Opere: Edizione Nazionale sotto gli Auspicii di Sua Maestà il re d'Italia, Vol. 6, Barbèra, Florence, Italy.

[371] Drake, S., 1957, Discoveries and Opinions of Galileo, Doubleday, New York.

[372] Cannone, M., and Friedlander, S., 2003, "Navier: Blow-Up and Collapse," Not. AMS, 50(1), pp. 7-13.

[373] Picon, A., 1988, "Navier and the Introduction of Suspension Bridges in France," Construction History, 4, pp. 21-34. 